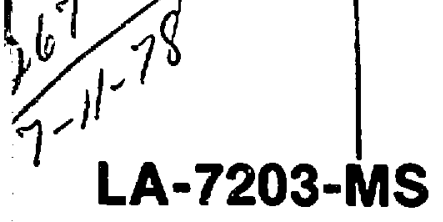

Informal Report

\section{An Overview of LAMPF and Its Accomplishments}

Louis Rosen
UC-28 and UC-34

Issued: April 1978

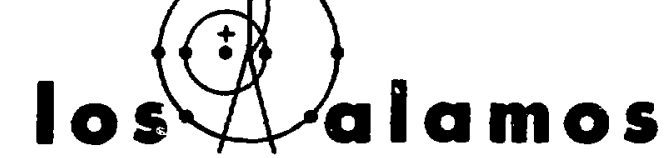

seientifie daboratory

of the University of California LOS ALAMOS, NEW MEXICO 87545

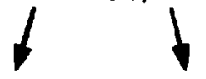

An Alfirmative Action/Equal Opporlunity Employer 
AN OVERVIEN OF LAMPF AND ITS ACCOMPLISHMENTS

by

Louis Rosen

ABSTRACT

This motre

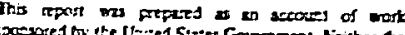

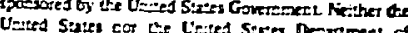

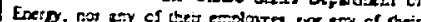

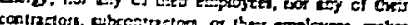

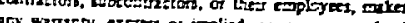

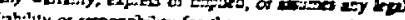

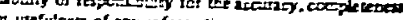

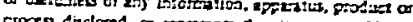

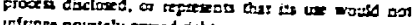

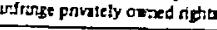

This report is from a talk given at a Los Alamos Scientific Laboratory colloquium on October 4, 1977, in which the history, technological accomplishments, present status, and scientific program at the Clinton P. Anderson Meson Physics Facility (LAMPF) were reviewed.

Even for laboratories as productive as the Los Alamos Scientific Laboratory (LASL) has been, it happens only once in $5 \mathrm{yr}$ or so that a really large gamble pays off in full measure. The Clinton $P$. Anderson Meson Physics Facility (LAMPF) now turns out to have been such a gamble. That the gamble was taken at all is a tribute to the vision, and even more, the courage of Jerry Kellogg, Norris Bradbury, and of course Senator Clinton P. Anderson after whom the facility was named. LAMPF is the product of several hundred gifted and very dedicated people supported by the resources of a great laboratory and also supported by their families whose sacrifices and understanding have helped to make this facility successful. LAMPF is an accelerator-based nuclear science facility. That's what it was designed to be. It was also designed to be the world's largest, most versatile, most sophisticated, and most powerful nuclear science facility, and it is also that. There are some other meson factories: one in Switzerland, one in Canada, and one now being built in the Soviet Union not far from Moscow. However, none of these, even the one presently under design and construction in the Soviet Union, will exceed LAMPF in capabilities. Already for more than a year the proton beams generated at LAMPF exceed in intensity all proton beams in the world from all the accelerators which operate above the pion production threshold, and I mean the sum of all the proton beams in the world. That is the nature of the facility you have here on this mesa. 
In the late $1940 \mathrm{~s}$ and through most of the 1950s, Los Alanos was probably the leading laboratory in the world in nuclear science. Admittedly LAMPF is an attempt to recapture this distinction. But why should we want to do that? Many of us, even $15 \mathrm{yr}$ ago, could see that nuclear science as a frontier scientific activity was going to die if there were not brought upon the scene new capabilities with which to unravel the riddles of the atomic nucleus. Why not let it die? I have been asked that question many times by people in the Congress, in the Office of Management and Budget, and the Executive Branch. I don't think I have to tell anybody in this audience that nuclear science is the mother of nuclear technology, and nuclear technology has al ready demonstrated to us the resour:es it provides for national defense and for other less-known activities: for medicine, for biology, for research in agriculture, and for industrial processes. Fifteen or twenty years ago we saw the nucleus as having great promise, not only for defense but in many other vital aspects of concern to our civilization. In my opinion most of these promises are being realized. Only in nuclear energy production for peaceful purposes are we behind schedule, and that is not for technical reasons. It is mainly for political and emotional reasons. I have to tell you, without proving it to you even if proof were possible, that in my opinion, there is no way this beautiful civilization of ours is going to survive in good shape over the next $50 \mathrm{yr}$ without bringing into our economy a very great measure of nuclear energy production; already $20 \mathrm{yr}$ ago many of us saw that. Many of us still are convinced of that today, because of the obvious utility of the atomic nucleus, and of the technologies which make use of that nucleus for defense and medicine and agriculture and industry and basic research in many fields, and also to step into the breach now as our major energy supplies are being depleted. For al 1 these reasons we felt, and were able to convince the Congress and the Executive Branch, that a high level of accomplishment in nuclear science, and therefore in the technologies that flow from nuclear science, is absolutely essential. for the well-being of our country and of all of western civilization. So much for the commercial.

Because we were able to convince the powers that be nationally that indeed the nuclear science venture is one that must be pursued, we obtained funds to pursue it, and everything that will follow in this talk evolved. It was in 1969 that LAMPF looked like this (Fig. 1), a channel we started to dig with architect and engineering funds. I have since been told that was the first and last time 
such a thing took place. Today it is complete and looks from the air as you see in Fig. 2. Not only is LAMPF complete, but all of the add-ons which were voted by the Congress after the initial base construction project was authorized are now complete and operational. None of theri have failed in any serious way. In Fig. 3 we have the business end of the facility looking west to the .Jemez. Socalled add-ons which I talk about involve an isotope production facility, a High Resolution Spectrometer Facility (HRS), a Weapons Neutron Research Facility (UNR), and a number of smaller installations. To give you an idea of the magnitude of the project, the base cost of the facility was $\$ 57 \mathrm{million}$; the add-ons plus development costs, plus instrumentation, doubled that base cost, all according to plan. At this moment we have a facility which cost about $\$ 120$ million to build, and would cost twice that much if we started today to reproduce it.

Figure 4 shows the birth certificate of LAMPF. It tells the budgetary history of the construction. Bob Warner, the LAMPF Budget officer, got this just the other day but it is a facsimile because the original had a 32 cent error out of some $\$ 57 \mathrm{million}$, and they would not give it to us. It has to be redone. This $\$ 56.99$ million represents the ba-se construction costs. In 1964 we roquested $\$ 55$ million. However, because of several years' delay, Congress voluntaril $;$ added $\$ 1$ million, making it $\$ 56$ million, and then Johnny Abadessa not so voluntarily added another million which is the sum for which the facility was built. Once Norris Bradbury had Johnny Abadessa here for a colloquium and afterwards brought him out to see the facility. When he started to introduce me Johnny said "never mind, I know that guy--everytime I see him it costs me a million doilars." And he was about right.

Figure 5 shows you some of the major technical advances made in accelerator technology during the time of development of LAMPF. Many of them are much more remarkable than $I$ have the time to describe to you. We start at the beginning with the injector system, and we have here not one injector but three. We have one for negative hydrogen ions, one for positive ions, and one for polarized hydrogen ions. Again, these are negative. These three injectors permit us the capability, which we have achieved, of operating two beams simultaneously, one $\mathrm{H}^{+}$, one $\mathrm{H}^{-}$. We are the only facility to have achieved this feat. To understand what a feat it is you must recognize that the linac is one-half mile long. This means that you have to keep particles going in a straight line for one-half mile. Now usually you do it by steering them magnetically. However, if you steer a positive ion beam in one direction, and there is a negative ion beam there, it will go in 
the opposite direction, so you must overcome this small problem. That we have been able to do. I have not the time to explain the sophisticated beam dynamics which go into solving this rather subtle problem, but a lot has gone into it. .Just in the last few months we have achieved a polarized hydrogen ion beam and that too is simultaneously accelerated with a positive hydrogen ion beam.

The next really major advance came in the drift-tube section (Fig. 6). The accelerator is in three stages: an injector, a drift-tube accelerator going to $100 \mathrm{MeV}$, and then a waveguide accelerator going from 100 to $800 \mathrm{MeV}$. In all of this accelerator, you must not lose, in places where you don't want beam loss, more than $1 \%$ of the beam. We are trying to keep beam losses well below $1 \%$, and that represents the big technological difficulty which such an accelerator presents. The reason one cannot lose more than $1 \%$ of the beam is that, if you do, you will induce radioactivity, which will prevent maintaining the accelerator, not to mention radiation damage. We have our share of these problems in those areas where we must dump the beam, where we must have a target, where we must have a beam stop, and where we must have isotope production stringers. Basically the drift-tube accelerator looks like an Alvarez structure, but Don Swenson and Ed Knapp figured out a way to introduce post couplers which, for those of you who know, convert the structure from a $\pi$ mode to a $\pi / 2$ mode, and for those of you to whom that doesn't make sense, let me say that with these simple posts they were able to increase the stability of this part of the accelerator by a factor of 100 . When you fill it with energy, instead of filling like an arroyo, where you have a flood in the form of a wave coming at you, this fills like a bathtub and it is a much more stable situation.

Figure 7 shows the major part of the accelerator and this was invented right here at Los Alamos. Darragh Nagle, Ed Knapp, and their colleagues invented the structure, and Don Hagerman, Tom Boyd, and Bob Jameson invented the rf systems which are essential to energize this structure. Later I will tell you about some of the remarkable spin-offs from this development.

In Fig. 8 we have the business end of the accelerator. These are the experimental areas. Without these no accelerator makes much sense. Here the main objective was to provide as many spigots as possible which could be independently utilized within the constraints of our budget. We did very well. If one goes out to LAMPF on a typical day when the accelerator is operating, he will find an average of 10 groups from various parts of the country working independently 24 hours a day on these various beam channels. The two beams, $\mathrm{H}^{+}$and $\mathrm{H}^{-}$ions, come 
into, and are sorted out at, the slitchyard. The ncgative ions go one way and the positive ions go arother, most of then straight ahead. One to ten percent of then can be deflected under the roadiay to the ixR. As we look at these spigots, in a number of cases the main proprietor is some other division in the laboratory other than MP Division. For example, the WNR is a P Division responsibility. The Nuclear Chemistry Facility and the Isotope Production Faciiities are the responsibility of CNC Division. The Proton Radiation Damage Facility, which you cannot see in this figure, is the responsibility of CMB Division. Other divisions also, with lesser responsibilities, make use of this facility. The HRS, called beam Area $C$, is also visible. There we study proton nucleus interactions with highenergy protons, $800 \mathrm{MeV}$ and lower. This is a variable energy machine, although so far we have used it mainly at $800 \mathrm{MeV}$. The neutron area in this figure has been mainly utilized by P Division. Jim Simmons' group is doing some beautiful neutron-proton studies which are now entering a stage where they will use a polarized hydrogen target. In nuclear science, as in any science, one has to start with first principles. In the nucleus the first principle is, how do the nucleons interact with one another? We can't see this very well inside the nucleus so we look at it in the free state with free neutrons and free protons and ask, what is the neutron-proton, neutron-neutron, and proton-proton interaction? Over the next 5 to $10 \mathrm{yr}$, we are going to solve that problem. We are well on the way. All that people have achieved so far have been quite good proton beams, not so good neutron beams, and some polarized targets. We enter the fray now with extremely precise, almost Van de Graaff quality, proton and neutron beams. Half a mile from the injector the proton beam can be a few millimeters in diameter and with as good emittance as any Van de Graaff can give you. In addition, we now have polarized targets and polarized beams, and that's as good as one can do. If one does not solve the nucleon-nucleon problem with those capabilities, forget it. We think the problem will be solved.

There is also an area exclusively for nuclear chemistry. This is the thin target area where we bombard heavy targets with protons and make nuclides never before seen. Also shown in Fig. 8 are areas for the biomedical people, for the nuclear chemists, for the weapons people, and for the chemists and metallurgists. Our philosophy has been to provide separate but equal facilities. This is very important. Prior to LAMPF, the nuclear chemists have been second class citizens at all major accelerators. Not so here. We went to George Cowan, to H Division, and to P Division and said, "Here is your chance. What do you want?" And each 
of them specified what they wanted in the way of facilities and buildings for their people, and they got what they asked for. From the thin target area we go to a succession of targets which are traversed simultaneously by the beam and these are basically pion production targets. The first target serves two pion channels, one of them with a marvelous spectrometer just now coming into use. A second target feeds one channel for high-energy pions and another for muons. The pion doesn't 1 ive very long. If you give it a chance, it will decay into a muon. We give it a chance and then use the muons. P Division and the chemistry people have made marvelous use of these stopped muons. Then we go on to the Biomedical Facility where patients already have been treated with pion beams. Things here look very good. Finally, we come to the beam stop area, but before we let the beam die, the nuclear chemists again come in to produce radioisotopes for various purposes such as medicine and defense. Quite recently a very important production run took place to solve a weapons problem which just had not yielded all these years. We also have neutron beams here for neutron radiation damage studies, although that has not yet been fully utilized. We also have a neutrino facility which is being used for a very fascinating experiment which will be discussed later.

In Fig. 9 are found the milestones which have been achieved during the past $10 \mathrm{yr}$ in the development of LAMPF. It should be pointed out that major construction funds were not released until October 1968, after which we had an unbroken series of successes. On June 10, 1970, 5-MeV beam was achieved. In August 1971, $200 \mathrm{MeV}$, and $800 \mathrm{MeV}$ in June 1972. In June 1972, we had a dedication of the facility. The first simultaneous beams, $\mathrm{H}^{+}$and $\mathrm{H}^{-}$beams, were achieved in 1973 , and in February 1974 beam to Area A East, which is the farthest experimental area. There is also pictured an equally important series of accomplishments which terminate in the most recent one, operation of the facility at $225 \mu \mathrm{A}$ of beam, just this year. As you follow these milestones, you see vastly different kinds of activities: design, engineering, construction, and finally learning how to operate and improve the machine. We are now actively utilizing it. The great variety of activities has put enormously incense pressures on our people, who essentially have to change jobs every 3 or $4 \mathrm{yr}$ and right now they are in the midst of another change. Normally, in such an endeavor, you would build your machine end then have the people who just built that one go off to build anuther machine. A new set of people would be hired to learn how to operate the facility and then you would bring in a new group to utilize it. For various reasons, this was not feasible 
at LAMPF and it is also not very humane to tell people "you ha?'e done your job, goodbye, we really appreciate your efforts, but we have no more work for you." We didn't do that. We chose our people in such a way that we could retread ourselves every few years and it has worked very we11.

LAMPF is basically a pion factory and Fig. 10 says, "What is LAMPF good for?" When I was younger, I thought there were four forces of nature. I think I always knew that, but I thought there would never be any more. I am not so sure of that anymore. Nonetheless, right now, we only have these four forces: the strong nuclear, the weak nuclear, the electromagnetic, and the gravitational, and we have to live with them and try to understand them. We have to try to understand the laws which govern those forces, and how do you do that? You understand them by somehow probing them. To probe them, you can't use your fingers. They are too big. You must use probes which have the scale of the range of those forces. Those forces have ranges; the strong nuclear ones, for example, like one fermi, so you must use probes which have a wavelength given by their momentum which is in that order of magnitude. Here are the probes which LAMPF generates. For strong nuclear forces, we have nucleons and $\pi$ mesons; for the weak nuclear forces, we have muons and neutrinos; and for the electromagnetic, we have anything with a charge. So these are our probes. To interpret what the probes tell us we use mathematical tools. Our mathematical tools must be understood, and we want to determine the limits of their validity. Some of these tools are quantum mechanics, quantum electrodynamics, and gauge theories which try to unify the weak and the electromagnetic interaction. We use relativity all the time, but we are not doing anything to improve that theory. So these are the intellectual purposes of LAMPF. LAMPF is justifiable completely in terms of its intellectual objectives but not everybody believes that or agrees to it, and so we have other objectives which are practical in nature. If a Congressman, for example, believes that if he becomes ill he might be helped at LAMPF's Biomedical Facility, we have made an important impression. Some of the practical things are in biomedicine, radiobiology, pion therapy, isotope production for radiopharmaceuticals, and isotopes for national defense. The WNR is likely to have very great importance, especially if there is a conpiete test ban, which looks probable. It will be one avenue available for maintaining a reasonable level of capability in activities which involve our nuclear national defense community. WNR will be very important for neutron transport measurements, vulnerability studies, and to test instrumentation and codes. There is also an enormous future for solid state physics using 
very low energy neutrons and this will be pursued. However, in order for the hil to really reach its potential, we need a storage ring. The Russians have understood this, and they are building their storage ring along with their meson facility. We have not yet been able to make this completely understandable, but we are going to.

There is also radiation damage. Some years ago when $I$ was worrying about my grandson's future, I asked myself the question, "Dc we really have to wait for years after we put materials in a reactor to see what the radiation damage is and then develop a better material?" It occurred to me that maybe we could use our very intense high-energy proton beams for this purpose, and the CMB people agreed. Alton Coulter from the University of Alabama laid the theoretical frameyork which showed that this idea was worth pursuing and now R. D. Baker and the CMB people are focusing a major erfort at LAMPF on proton radiation damage studies.

The picture on Fig. 11 appeared some years ago $\mathrm{O}$ il the cover of the Journal of the American Physics Teachers. This is designed for those of you who do not work with pions everyday to tell you pictorially what we think the main function of the pion is. Namely, it is the quantum of the strong nuclear force, the messenger of the nuclear force. It is tightly bound, but when we put a few hundred $\mathrm{MeV}$ into a nucleus, you can break these bonds and you make these pions, and then you can go ahead and have fun with them.

Figure 12 indicates the kinds of experiments now going on. I would like to give you a broad brush view of a few of them. The rage right now in particle physics is colliding beams. We don't have enough money to build a colliding beam facility so we do it with mirrors. In the last few years there have been some beautiful quantum mechanical calculations on the negative hydrogen ion, on the resonances in the photodissociation of that ion. You know the second electron is held only by about three-fourths of an electron volt. We think we know all about electromagnetic forces and so, in principle, quantum mechanics should tell us everything about that negative hydrogen ion, and quantum mechanics predicts that there should be resonances in its photodissociation. Now where does it predict they occur? It predicts they occur at about $11 \mathrm{eV}$ and a $1 \mathrm{ittle}$ below $11 \mathrm{eV}$, just above the channel for breakup of the negative hydrogen ion into an electron and a hydrogen atom. Experimenters from the University of New Mexicu and LASL invented a beautiful way to look at quantum mechanics in this context. They start with a laser beam which has an energy of 3 or $4 \mathrm{eV}$. What is needed is a continually variable energy with very high precision from about 1 to $12 \mathrm{eV}$. They 
achieve that by causing this laser beam to intersect the proton beam. By varying the angle of intersection, they can vary the center of mass energy from 2 to 12. $\mathrm{eV}$ with marvelous precision. They do this with a mirror system. As you rotate the mirror, the intersection of the laser beam with the proton beam is at different angles, and you get these different center of mass energies. What do you look for? You look for the electrons from the dissociation of the negative hydrogen ions, as a function of intersection angle. A very simple experiment. Figure 13 shows you what they see.

As you get to $11 \mathrm{eV}$, you see this "shape" resonance, and quantum mechanics tells us that it occurs because of the retardation of the quantum mechanical wave of a free electron--any free particle, when it confronts a potential, which cannot bind it, with just the right energy. What you see in Fig. 13 was predicted. Then quantum mechanics also predicts some other resonances never before seen, called Feshbach resonances. These too have now been seen, and they have to do with the channel involving two electron systems and the hydrogen atom.

In Fig. 14 is illustrated the study of quantum electrodynamics by using the muonium atom, $\mu+\mathrm{e}-$. We are looking at the hyperfine splitting of the energy levels in the ground state of muonium and are measuring this frequency. We see that $\Delta v$ is known to enormous precision and predicted by theory to even greater precision. The experimenters were looking for the place where theory breaks down. From this splitting interval you can get the ratio of the masses of the muon to the proton, and you can get the ratio of magnetic moments of the muon to the proton. Figure 15 shows the history of $\Delta v$ measurements, and it is obvious that they have made a considerable advance. The last entry is the world average. Figure 16 shows schematically the Low Energy Pion Channel (LEP) and here is the first successful observation of double charge exchange, where a $\pi+$ enters the nucleus, comes out a $\pi$ - by interacting sequentially with two nucleons, and thereby changes the target nucleus to one which is two charges removed. Bob Burman and his collaborators have managed to use this channel as a double spectrometer. They use the first part of the channel to give $\pi+$ of a given energy, then the target gues in, and they use the second half of the channel to measure the energy of the $\pi-$.

Figure 17 shows their first results. At a recent conference in Switzerland these results were one of the star perfomners, because for the first time one sees not only a new nucleus which has never been seen before, namely ${ }^{18} \mathrm{Ne}$, but a double isobaric analog state going from ${ }^{18} 0$ to ${ }^{18} \mathrm{Ne}$. It is beautifully clean. 
Many people have been looking at muonic atoms, measurin" with great precision the $x$-ray spectrum which emerges when you form a muonic atom. A muonic atom is a marvelous thing. It is like a one-electron atom but the nucleus can be anything up to uranium, so it is basically simple. These muonic atoms, if you invoke the Dirac equation, will lead you to information on the charge distribution of the nucleus. This has been something we have been wanting to understand as long as there has been nuclear physics. So what does one do? One measures the energy transitions in these muonic atoms with very great precision. One can also measure the hyperfine splitting. For example, in ${ }^{165}$ Ho one measures the $3 p$ to 2d transitions. One measures the transition energies, and you then ask, "what kind of Fermi charge distribution do you need to put into your Dirac equation to yield the energy transitions that you measure?" The kind of distribution you need for ${ }^{165} \mathrm{Ho}$ appears to be unique. Figure 18 is a map of the charge distribution of ${ }^{165} \mathrm{Ho}$ in terms of the central region. Shown is the $90 \%$ density 1 ine, the $50 \%$ density 1 ine, and the $10 \%$ density 1 ine, and they are not even circles. That fact emerges as a result of the higher order moments, the F:-2 and E-4 moments. The High Resolution Spectrometer (HRS) is shown in Fig. 19. Shown are the dipoles. One uses a vertically dispersed beam, the dispersion matched by a quadrupole dipole-dipole (QDD) system, so that it can be used as an energy-loss spectrometer with energy resolution eventually down to $50 \mathrm{keV}$. Thus far on $1 \mathrm{y} 100 \mathrm{keV}$ have been demonstrated. This spectrometer can be utilized to make proton-nucleus measurements. Figure 20 demonstrates proton-nucleus scattering data. Shown is the cross section in millibarns per steradian as a function of center of mass scattering angle. Note the uniformity of this diffiaction pattern. One assumes a Fermi distribution for the neutron densities in the nuclens, and when you put in the proper distribution, the solid curve gives you what you should get for a given neutron density distribution in the center and throushout the nucleus. So here, perhaps, is the first real handle on mapping neutron distributions in nuclei. Plus or minus pion scattering and transmission measurements are another handle that has been used. By using protons, pions, muons, and electrons it may finally be possible to map both charge and nuclear matter, and identify fluctuations of the lensity of neutron matter in the nucleus.

One of the purposes of LAMPF which was promised many years ago was that it would bridge the gap between nuclear and subnuclear science. It is in fact doing that. In subnuclear science, as well as in nuclear, we have conservation laws. There are the great conservation principles, such as conservation of energy and 
conservation of momentum, but there are also others. There is, for cxample, the conservation of CPT, the product of time reversal, parity, and charge conjugation. It is a really important concept. We are loing work on those conservation lass. Usually $\pi^{\circ}$ decays to $2 \gamma$. If charge conjugation is not conserved, $\pi^{0}$ can decay into $3 \gamma$. My eminent colleague, Darragh Nagle, has explained to me that the good things in life are either illegal, immoral, fattening, or they have a very small branching ratio, and we are talking about the fourth good thing in 1 ife. Bob Macek and his collaborators have recently done the first stage of an experiment to look for $3 \gamma$ from $\pi^{0}$. There are other low-branching ratio experiments which are under way in which the first data have just been taken. We can predict from quantum electrodynamics $\pi^{0}$ to electron and positron decay without any $\gamma^{\prime} s$. The probability of that jecay can serve as a very sensitive test of some aspects of quantum electrodynamics. What is shown in Fig. 21 are some important cxperiments which are just now under way. Herbert Anderson, who is one of our eminent Fellows, is collaborating with the Chicago group, Hofstedter's group from Stanford, and Nagle's group here at LASl on an experiment which has to do with gauge theory. Up until recently and especialiy since \& , u neutrino was discovered at Brookhaven, most physicists believed that there was one conservation law for muons and another for electron leptons, and that these were separate and distinct. One could not mix then. Now the most modern and most believed gauge theories tell us that it is not forbidden to have the mixing of mion and electron lepton numbers; that conservation must not be separate for each and so the question comes up, "how can we validate or invalidate this predication of gauge theory?" It would be a very important experiment if it could be done successfully. There is now under way such an experiment to look at the decay of a muon into an clectron and a gamma ray. That would immediately prove the violation of separate conservation laws, and this experiment is now under way. Another one with similar thrust is the neutrino experiment.

The neutrino experiment is a test of muon conservation. We make pions, ${ }^{*}$ and $\pi^{-}$, in the beam stop. The $\pi^{-}$are absorbed. The $\pi^{+}$are stopped. They decay to $\mu^{+}$and to $\mu$ neutrinos. Now the $\mu$ neutrinos have an energy below what is necessary to make another muon so you can forget those. They will never appear again. The $\mu^{+}$decay to an $e^{+}$(a positron), an electro neutrino, and a muon antineutrino. That decay holds if lepton conservation is restricted, separ itely for muons and separately for electrons. If you fol!ow that electron neutrino and bring it into a water Cerenkov counter, you will see nothing because the clectron 
neutrino catnnut convert a proton to a neutroll. To do that you need an anticlectron neutrino and so if they see signals here, they will kncs that you have nonconservation of leptons in the usual sense. But suppose they don't see anything? How will they know that they would have seen something if there were something to see? In order to know that, you replace the light water with heavy water. An electron neutrino will convert a neutron to a proton. That has been seen before so we have a check on this experiment, if they see nothing. They are now well into the data-taking phase, and we should know within a ycar how this experiment comes out.

Figure 22 takes us to the domain of the radiochemists. Their separate facility just before Area $A$, the main experimental arra, was shown in Fig. 3 . They have a uranium target and time-of-flight paths and then equipment to measure $\mathrm{dE} / \mathrm{dX}$ and total energy. Shown in Fig. 22 is a mass spectrum of only the magnesium isotopes they see when they bombard uranium with protons, and the resolution is real. The data have not been doctored. They are just elegant.

Figure 23 shows some discoveries. Wherever there is a square, they have seen a new isotope. I must admit that it is not the same thing as discovering a quark or a parton or a monopole; on the other hand, nobody has discovered a quark or a parton or a monopole, so until that happens this is just like Columbus discovering new islands when he came to the new world, or going to the moon and discovcring craters. This is the stuff of which nuclear science is made. They are going to be able to look at the mass surface far removed from the line of stability.

Figure 24 shows something that is literally closer to your heart. They are radionuclides which are being made now, and which the nuclear chemists are learning to purify. They have definable uses, and we could use them right now. The chemists are making ${ }^{77} \mathrm{Br}$, which is a compound you can use to label estrone. They make a cow, a ${ }^{77} \mathrm{Br}$ generator which then gives you selenium, a metastable state of ${ }^{77} \mathrm{Se}$, and this is used in diagnosis. The hospital gets this ${ }^{77} \mathrm{Br}$ and when it needs selenium, it just milks the cow and has the needed element. This is a steroid and it could prove very useful. I have some personal reasons to think it would be marvelous if we could label steroids and know what they do in the human organism and where they go. Treatment of some rare diseases are now done almost blindly, by hit and miss, using certair steroids. So a steroid labeling compound could be very useful. 
Selenium-72 gives you "as for brain tumor localization, and "Sr gives you ${ }^{2} \mathrm{Rb}$, again through a cow for miocardial imaging, and that is why I said this is closer to your hearts that you might think. We have plenty of $1: 1$ l and are spending time, effort, and money to develop ${ }^{12}{ }^{3} \mathrm{I}$. Why ${ }^{123} \mathrm{I}$ ? The reason is that when ${ }^{131} \mathrm{I}$ is given to a patient, it provides a very high level of dose, 20 to 30 rem. Iodine-123 reduces that a factor of 50 and would make it possible, not only to reduce the level of radiation to the population, but to treat pregnant women and small children which can't be done now with ${ }^{13} I$. It would be a most worthwhile contribution to our arsenal of radiopharmaceuticals if we could have that. Copper-67 is used in labeling of gleomyacin. That is a chemotherapeut ic agent for melanoma and a very good one. It is also a trace element in the body. Ytirium-88 has national defense applications but is also useful as a photoneutron source for safeguards, which is also a national defense application. Aluminum-26 is used for geochemical studies.

Figure 25 shows a picture of the first patient being treated in the biomedical channel where the trick is to get the pions to stop in the tumor volume and no place else, if you can manage that. Why do we think from the physics standpoint that this is possible? Why did we recommend this kind of venture? Figure 26 demonstrates the reason. There is shown the survival of T-1 kidney cells in gelatin as a function of thickness. Here the relative dose is measurcd with ordinary dosimetry instruments. As a pion enters, the dose isn't very large, but where it stops there is quite a peak and the question is, can the peak be correlated with the killing power of the pion beam? For $x$ rays the survival is lowest at the surface and goes up as you get farther and farther into the gelatin. That is not what we want. We want the opposite. For pions, we do get the opposite. We get a small survival just where the peak is high for the stopped pions, and $i t$ is this peak we are trying to introduce in the patient under the channel shown in Fig. 25. It works. Dr. Kligerman has gotten some dramatic results. In Fig. 27 we see the Weapons Neutron Research Facility (WNR). Ed Knapp is the on-site manager of this cormplex which is under the auspices of P Division. This is a very powerful facility to do not only weapons-related work but also solid state physics with very low energy neutrons. The beam has been all the way down to the WNR since the first try. The line goes for several hundreds of meters. Here we expect to do a variety of neutron work.

I want to tell you now about some of the spin-offs to reassure you that basic science isn't always something that pays off $30 \mathrm{yr}$ in the future. It can 
pay off very dramatically very fast, and in the following examples that happens to be truc.

Damny Doss was an electrical engineer with Don Hagerman and Tom Boyd in designing and developing the rf systems for LAMPF. When that was finished, he wanted to pursue his ideas of using localized rf heating to control tumor growth. Pcople took hot baths hundreds of years ago for that purpose. It is not a new idea, but he had gained some new insights from his experience in control of $\mathrm{rf}$ so that this could be done in a highly controlled way. The circuit he uses is very simple. There are two electrodes and a few MHz generator and you bring the energy into the volume and then you raise the temperature locally to about $45^{\circ} \mathrm{C}$. If you beljeve the literature, this should do some good.

The device that Danny developed in collaboration with others from LASL and UNM is shown in Fig. 28. It is small cnough to be plugged into an autnmobile cigarette lighter, from which he gets all the power he needs to operate it. Figure 29 shows an example of an eye tumor which is very prevalent among cattle in the southwest. It is a several million dollar per year difficulty in the southwest. The next figure shows tre same tumor after 10 weeks of treatment (Fig. 30). The tumor has disappeared. It isn't necessary for that cow to live $100 \mathrm{yr}$. If the tumor is taken care of for the commercial 1 ife of the animal, our purpose has been achieved.

The statistical results of this experiment are truly amazing. They now have treated many eyes. The LASL group has treated 106 with a 70 to $90 \%$ remission. Gogan Ranch in Texas has treated 31 with a $61 \%$ remission and $29 \%$ regression rate. People at New Mexico State University treated 22 , and they had $73 \%$ remission.

Another spin-off is the radiation therapy units which are being built a11 over the country, and which use the developments at LAMPF in the waveguide portion of the accelerator. One of these units can now be found in almost every major radiotherapy clinic or hospital in the country (Fig. 31).

We do have our problems and one of our problems is achieving remote maintenance of highly radioactive components (Fig. 32). This is a problem which will set the limit on what you can do with facilities such as LAMPF. The radiation levels are such that no one can go down there to fix things. So we sponsored the development of force-reflective servomanipulators. We recently received the first one commercially built in this country. With this instrument, you do some- 
thing and it feels as though you are down there in that valt doing it sith your hands, but you are $100 \mathrm{~m}$ ahay.

What about the political status of LAMPl? ligure $j 5$ shows the regional distribution of users. There are almost 1000 members of the Users Group and they come from all over the country and from some foreign countries as lieil. This year thus far we have taken data on 73 experinents involving 350 experimenters coming from 71 institutions. Don Hageman, Joe Bergstein, Jerry liallace, and Lew Agnes and his group have operated this complex facility with better than $80 \%$ reliability. They have provided $20800 \mathrm{~h}$ of beam time to the various experiments just so far this year.

Figure 34 shows what we promised ERDA. During the past year we were supposed to achieve $100 \mu \mathrm{A}$. In making these schedules we used what George Gamov used to call the Russian system. We promised to do next year what we were reasonably sure we could do this year in order to avoid putting people under any more pressure than necessary. For this reason we are now ahead of schedule. Whereas we should be at $100 \mu \mathrm{A}$, we have been running at 225. Whereas this fiscal year we are supposed to go to $300 \mu \mathrm{A}$, we think we may be able to start at $300 \mu \mathrm{A}$, but this is the only way to deal with such a complex facility. Basic research and complex technological developments cannot be scheduled the way one schedules automobile production.

In Fig. 35 we show cumulative LAMPF beam for experiments. Sl.own is the number of 8 -h shifts. So far we have had 80008 -h shifts on all experiments which have been under way, and as of right now we have provided 4 A-hours of $800-$ $\mathrm{MeV}$ protons to the various experiments.

What is LAMPF's status politically? Last month there appeared a report of the ad hoc committee on the Future of Nuclear Science. This is a National Academy Committee which met for $2 \mathrm{yr}$ to assess, evaluate, and project the future of nuclear science. Now what they say is this: "The major facility in this area (medium energy physics) of nuclear science in the United States is the $\pi$ meson factory at Los Alamos with $800 \mathrm{MeV}$ primary proton beam. With LAMPF now operating at the $150 \mu \mathrm{A}$ level a new era of nuclear investigations is beginning as we have indicated previously. Therefore more effective utilization of LAMPF must be given high priority." And so what is their recommendation? "lie strongly recommend significant incremental funding for operation and support for experiments at LAMPF as detailed, etc.,... The expansion of the use of LAMPF will require construction of a staging area." 
Figure 36 shows the budgetary history of LAMPF and a personne $\mathrm{history}$. The top curve, which is personnel, has leveled off for budgetary reasons. The budgets continue to rise. The problem is approximately $20 \%$ of our costs are utility costs which are rising much faster than inflation, which determines the budget rise. That is why we have a deficit right now of about 50 people who are needed to properly use the facility. For this fiscal year we have about a $\$ 22$ million budget and about 340 people.

Figure 37 shows another spia-off. If the $\pi$-meson therapy goes the way it appears to be going, about 10 pion therapy generators will have to be built in the next couple of years. We plan to design them so that they can be built for about $\$ 10$ million each. The National Cancer Institute has commissioned us to develop a machine for that price. The principal investigator for this work is Ed Knapp and the work is being done in MP-14 under the direction of Don Swenson. This machine is a variant of LAMPF in some very important ways which will make it much more economical and much simpler since it is a single purpose machine. If the NCI should decide they want neutrons they can take our development and slice it like a sausage. If they slice off the first part they will have a neutron machine.

The LAMPF accelerator is a very complex development but also a very successful one so complexity doesn't necessarily have to go with nonsuccess. 


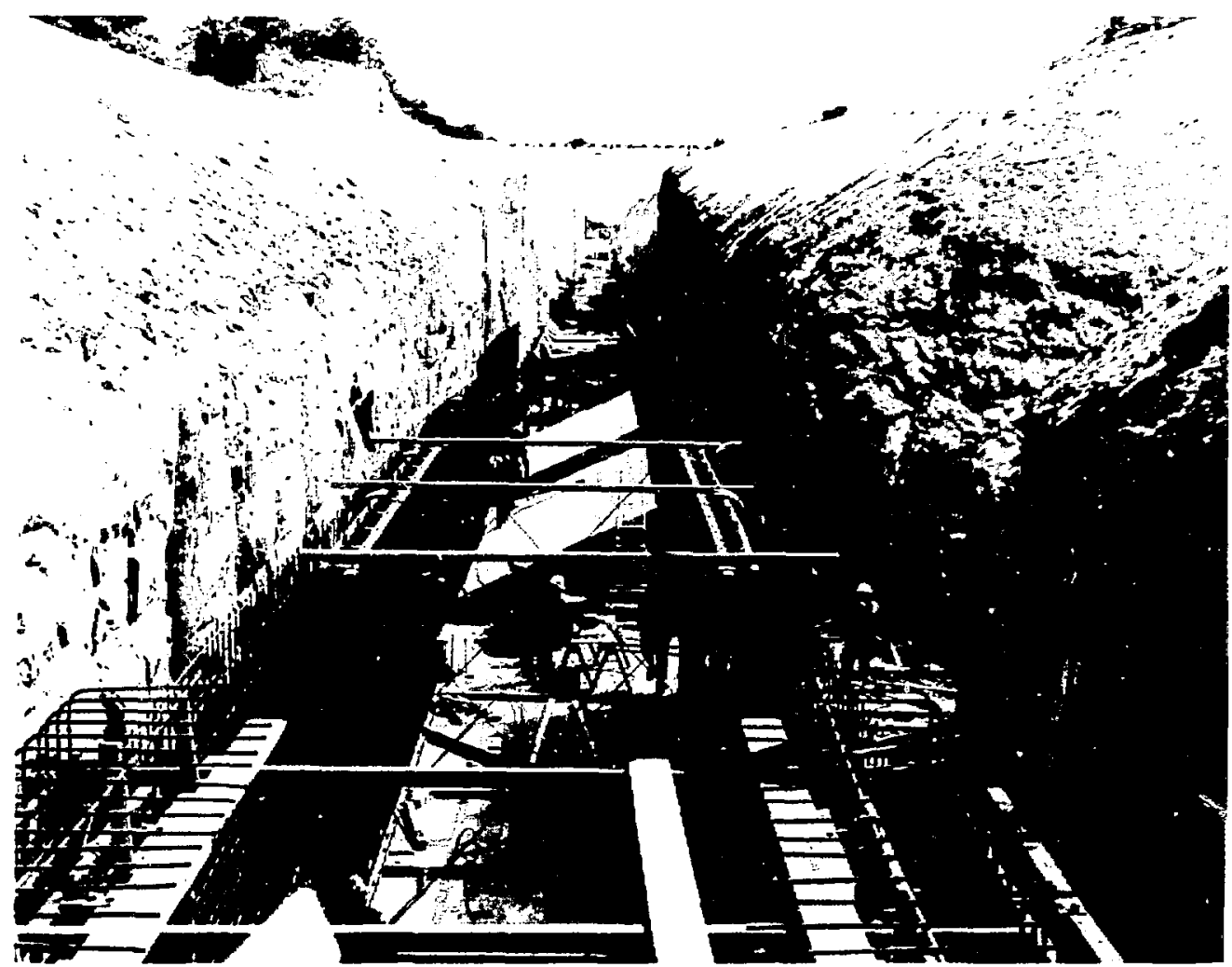

Fig. 1. The beginnings of LAMPF (1969).

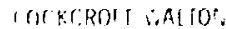

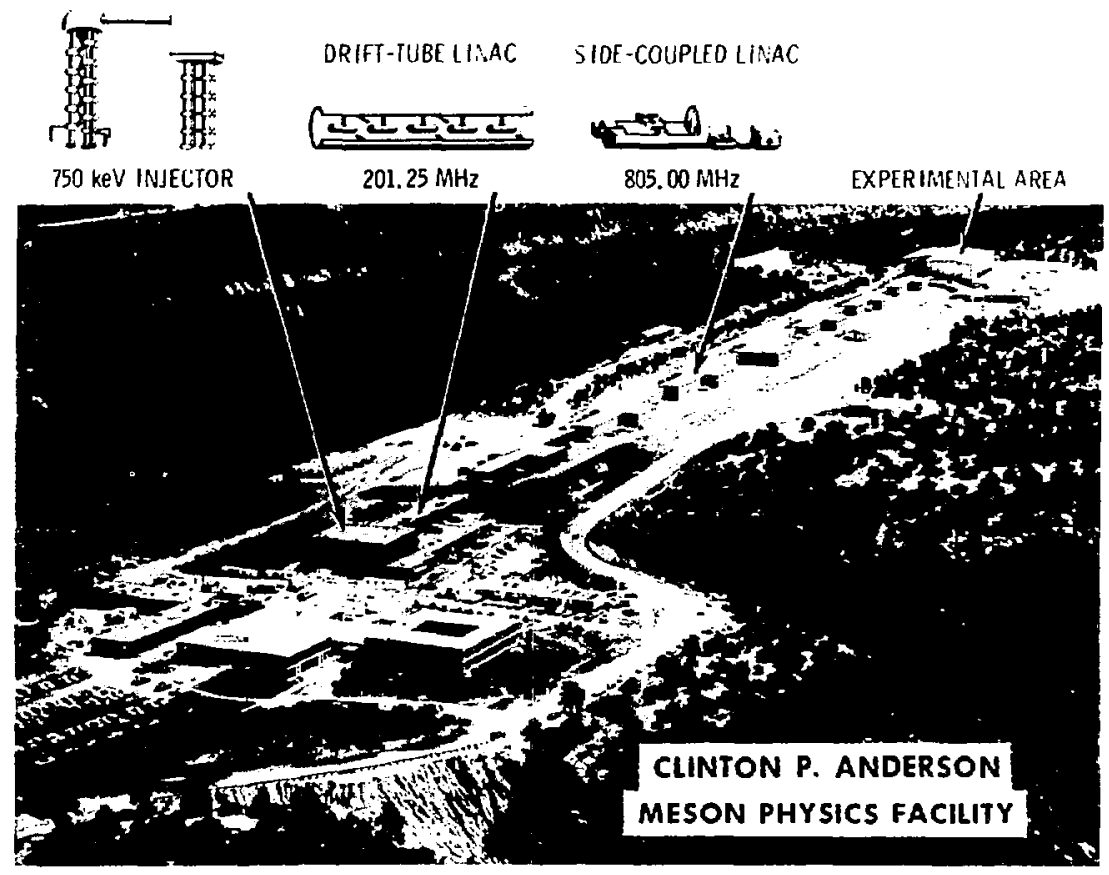

Fig. 2. Aerial view of LAMPF today. 


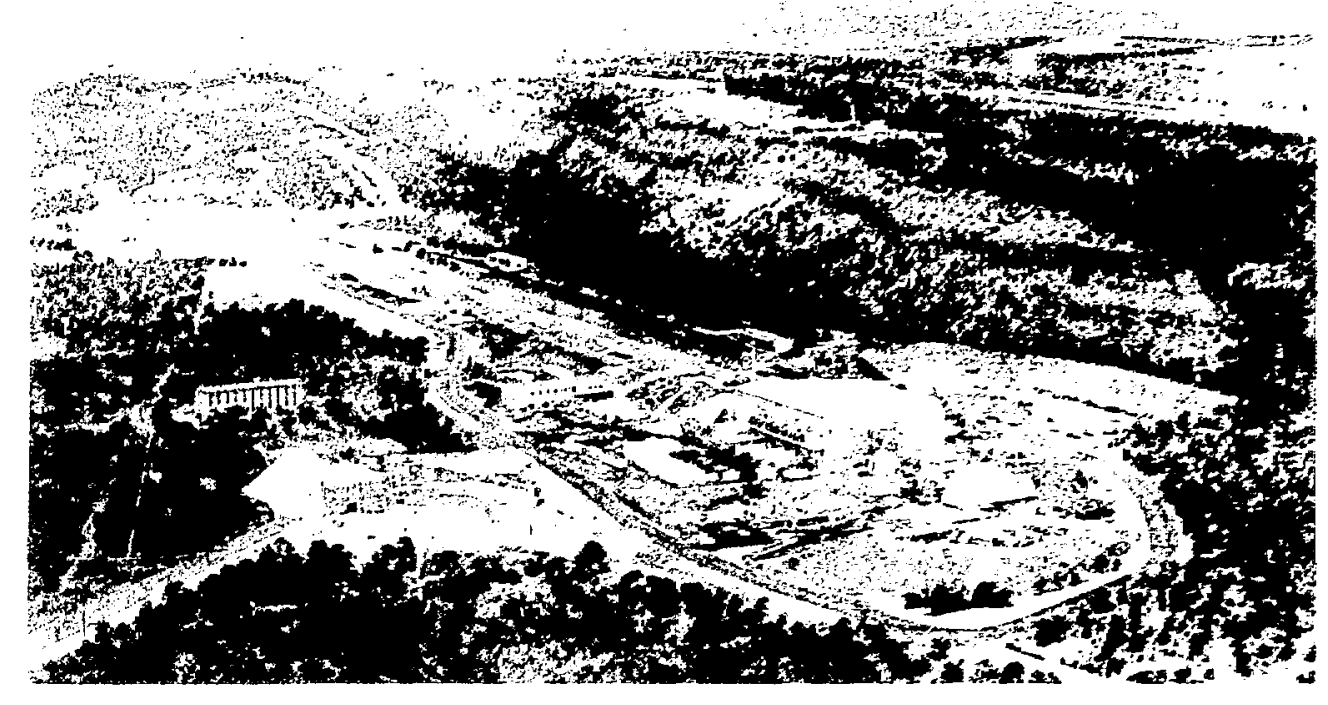




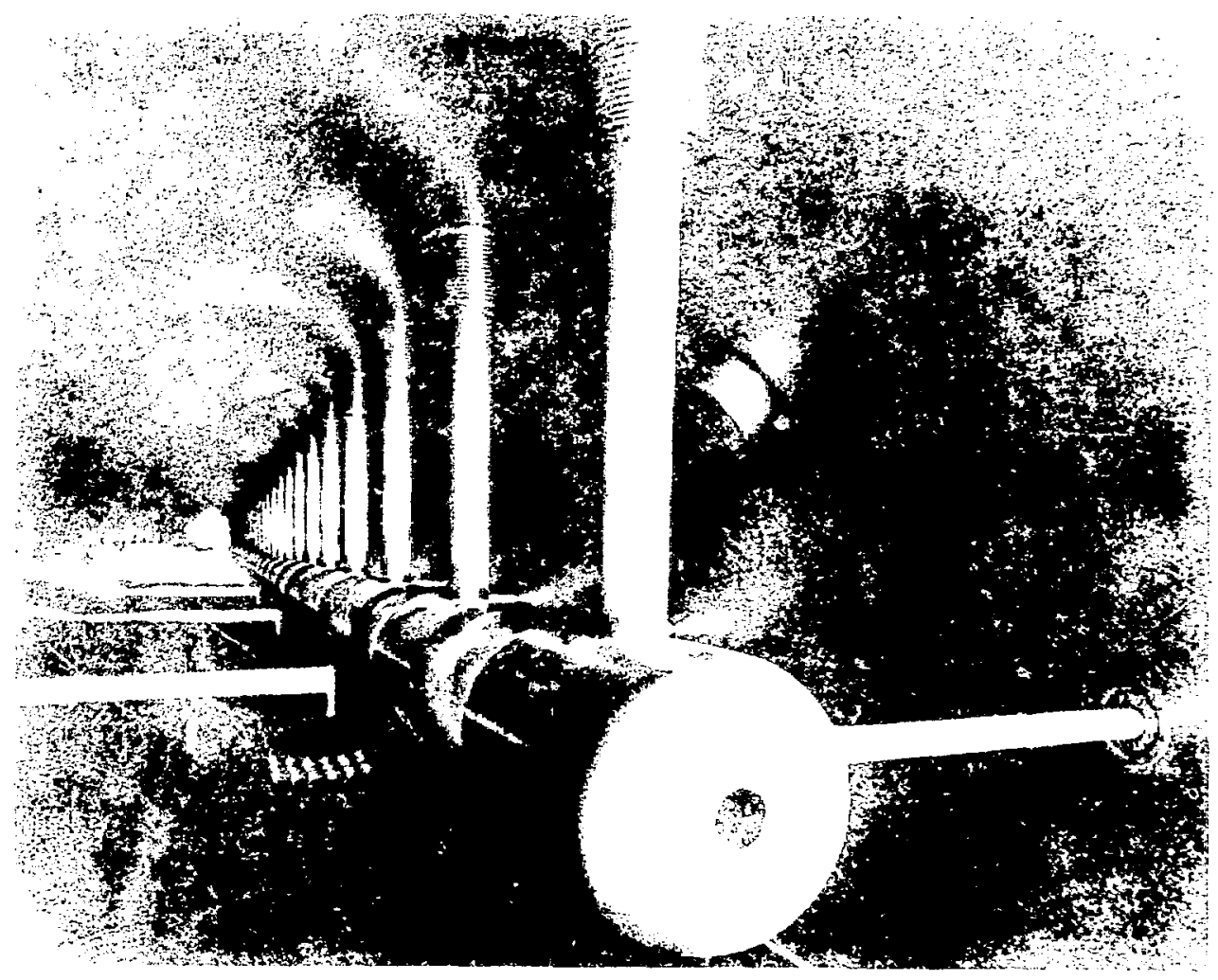




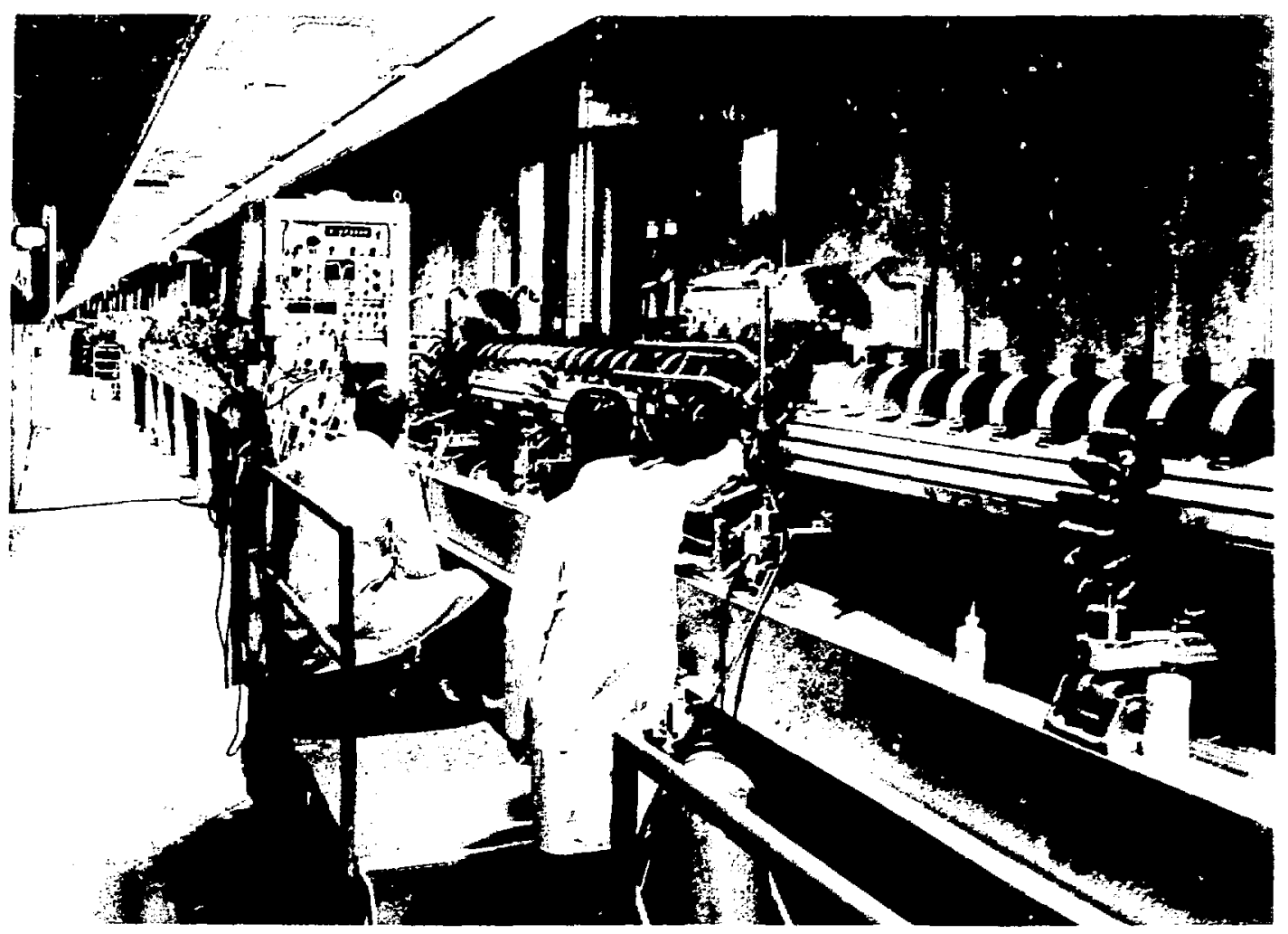

Fis. 7. Major part of the accelerator.

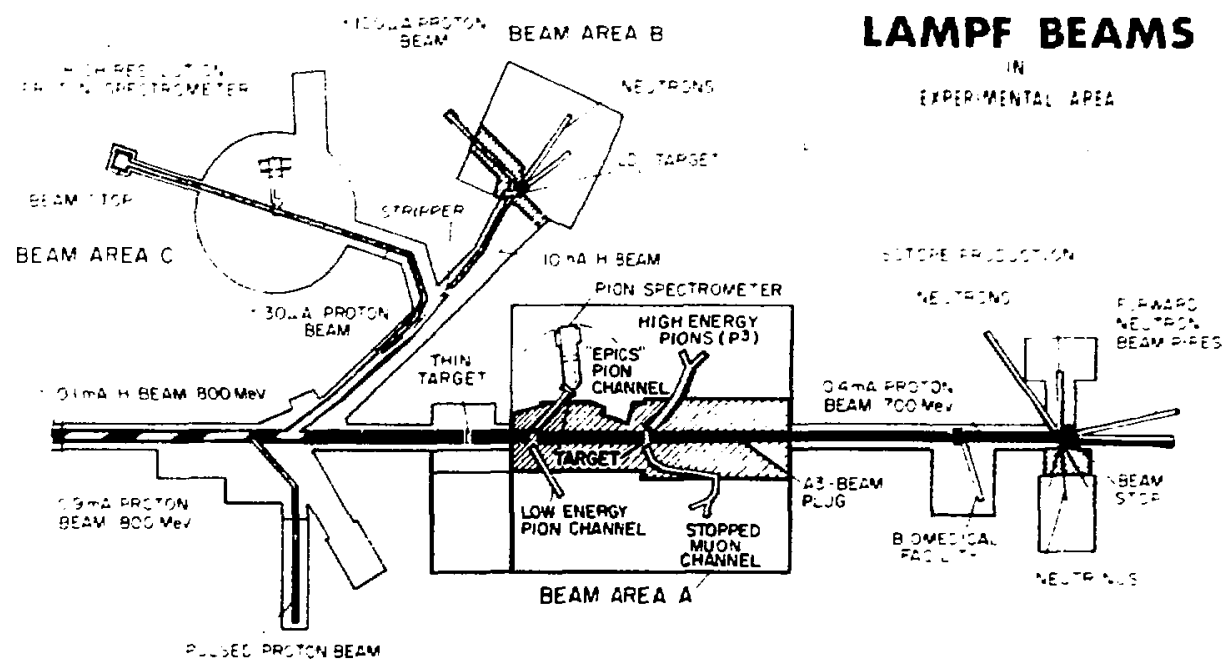

\begin{tabular}{|c|c|c|c|c|c|}
\hline 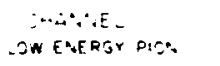 & $\begin{array}{l}E+50 ;, \cdots e . \\
0-300\end{array}$ & 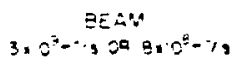 & 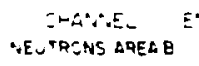 & 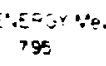 & e $3 E \therefore \square^{\circ}$ \\
\hline -GU E"AERGY PION.P" & cos 500 & $0 \rightarrow 1, O R+0^{3}-1 / 2$ & NEJ PRONS BEANSTOF & $=-20$ & $\because \therefore \mathrm{s}:$ \\
\hline$E=\operatorname{CS} P \cdot \operatorname{\theta EAAX}$ & 50300 & $4 \times 10^{6}-1,3$ OR $10^{\circ} \mathrm{T}^{-s}$ & EIOMEDICAL & 90100 & $2 \cdot 10^{2}-1 / 5$ \\
\hline SECPPET MUON & $0: 65$ & $5.0^{\circ} .^{\circ}, 5210^{\circ}$. & NEUTAINOS & 2050 & $5 \times 10^{\circ}, 1 \mathrm{~cm}$ \\
\hline
\end{tabular}

Fig. 8. Experimental areas of LAMPF. 


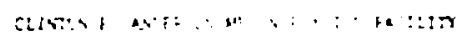

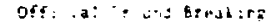

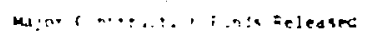

t.unb Eeca diticered

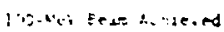

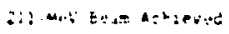

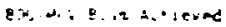

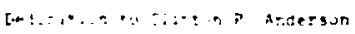

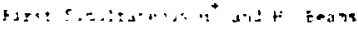

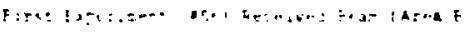

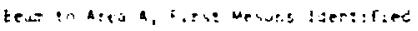

beux ic Ared A East

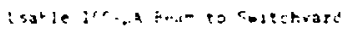

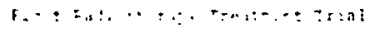

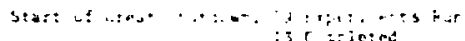

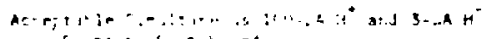

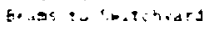

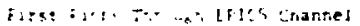

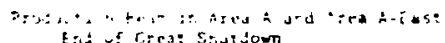

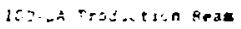

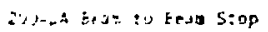

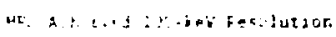

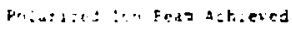

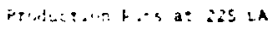

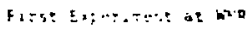

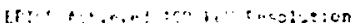

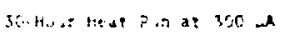

Fig. 9. Milestones.

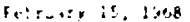

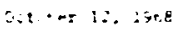

ixe $20.1 \pm 0$

3ixe 21.1901

Ausios: :- 1901

Jisie 9. 1972

sencenes 29, $19 \%$

Mor 4. 1575

Aintest 29, 1903

ancse $26,19: 3$

festrusty 6, 1904

soptetier S. 1974

axcose $: 1,19: 4$

ces-ber 24. 12,24

Eprothe: 14.:975

Har:s 19, 19:6

Mir:is. $19=0$

A. insse $15,19^{\circ} 6$

arrices $23,19^{-6}$.

screster 1. $19-6$

A: rd: :0, $13: 7$

Sure 5.1970

suig is. :977

audst: :0, : $3^{\text {Th }}$

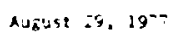

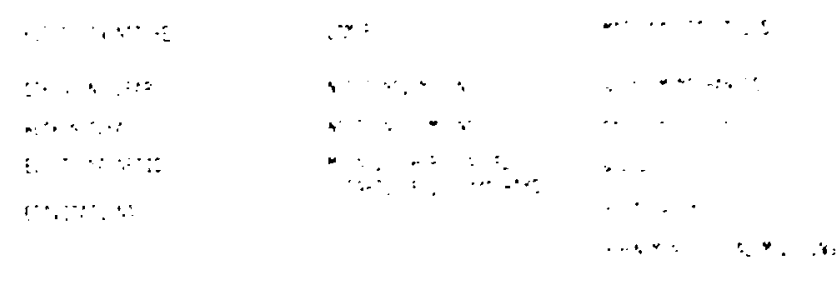

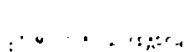

ij: : :

$\because \because A \quad \therefore$ in $: 2 r$

$\because, \quad 1=$

$\because \because: \therefore: \because: \because \bar{x}$

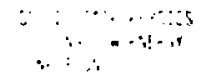

Fig. 10. What is LAMPF guod for?

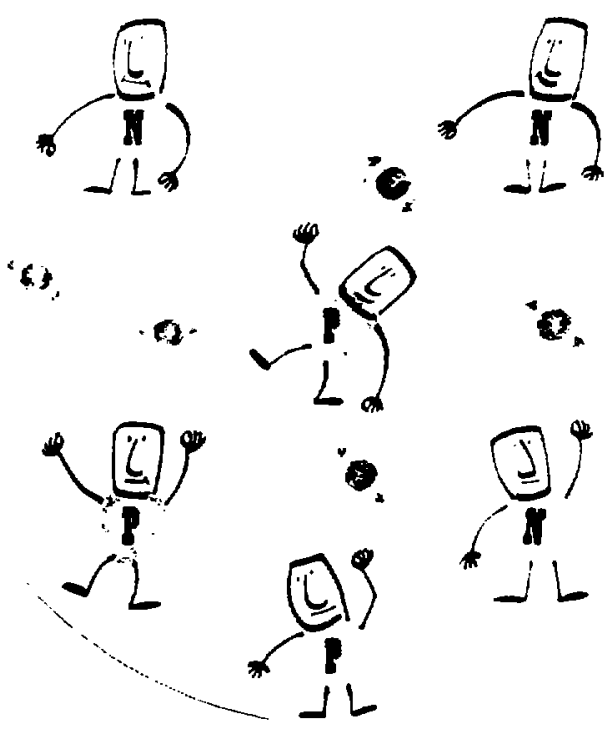

Fig. 11. Pictorial explanalia: of the pion. 


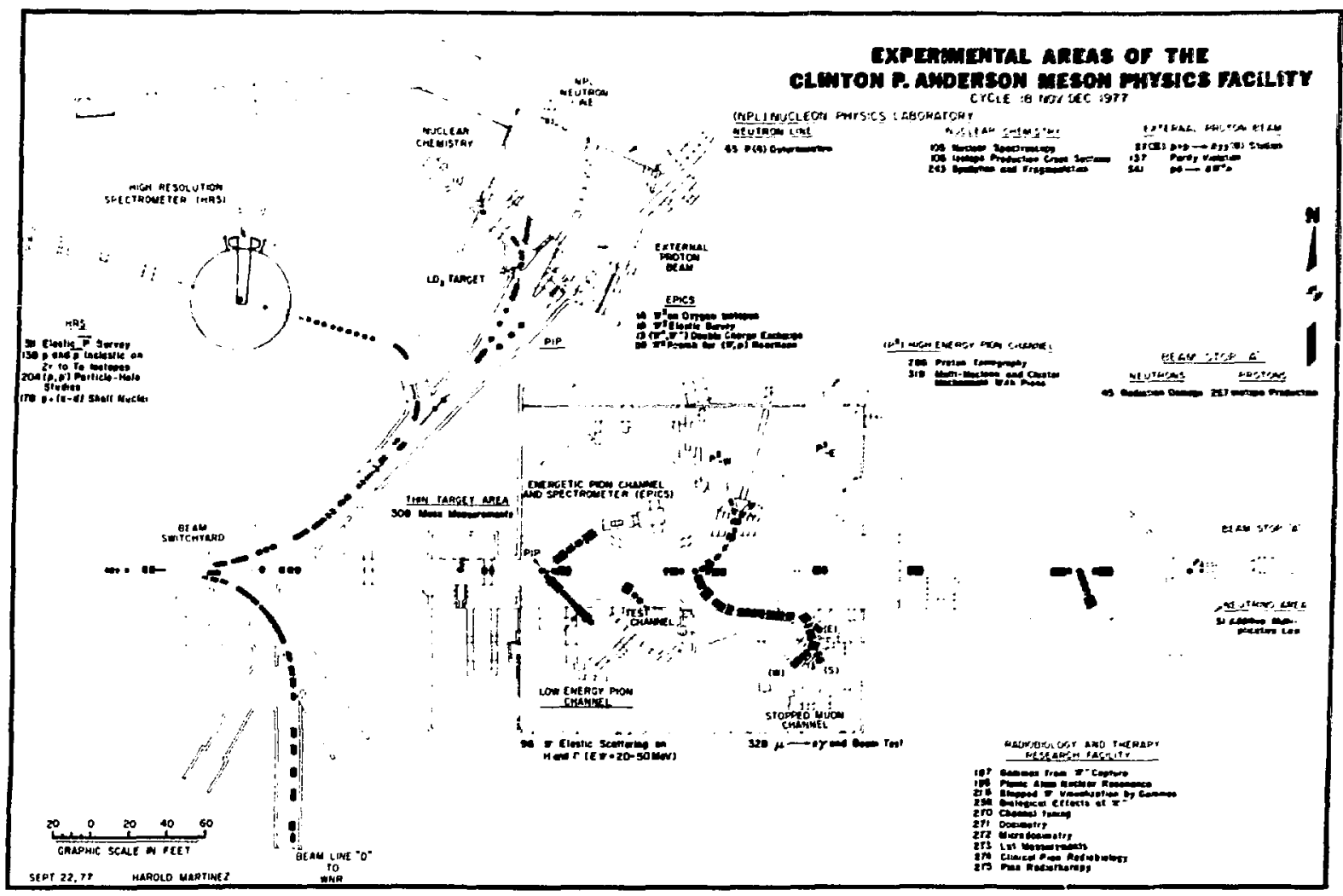

Fig. 12. Kinds of experiments going on at LAMPF. 


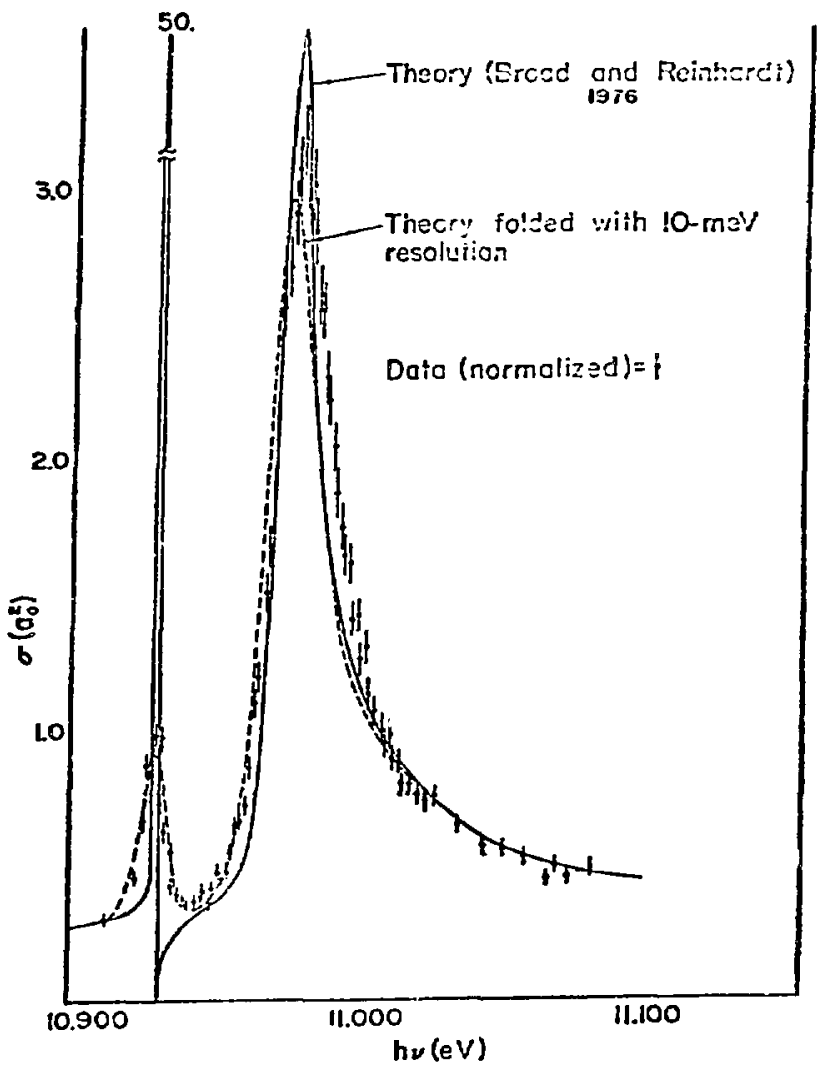

Fig. 13. Resonances in photodisassociation of negative hydrogen ions.

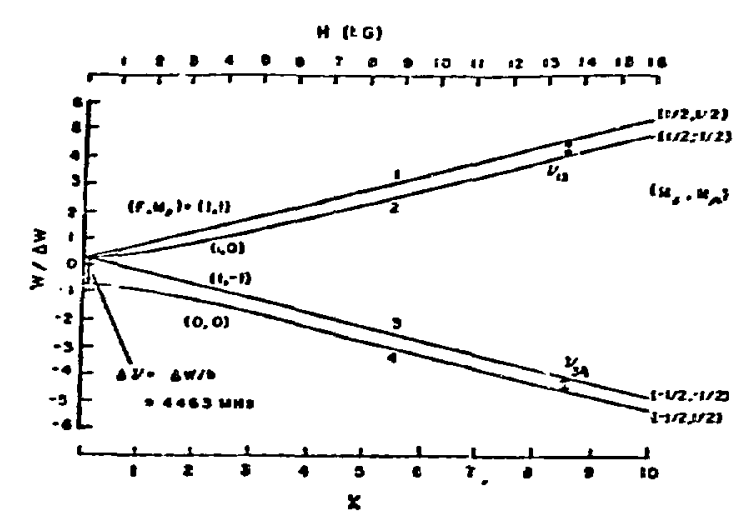

Enerdy Level diagras for liuonitu= in $2^{2} 5 / 1 / 2$ state

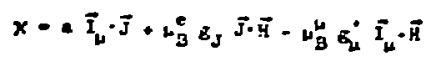

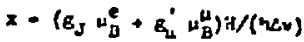

High Field Results:

$\Delta \nu=4463 \quad 302.35(0.52) \mathrm{kHz}(0.12 \mathrm{ppm})$ $\Delta \nu_{\text {Theory }}=4463 \quad 318.5(6.5) \mathrm{kHz}$ $\mu_{\mu} / \mu_{p}=3.1833403(44) \quad(1.4 \mathrm{ppm})$

Fig. 14. Energy level diagram for muon ium. 


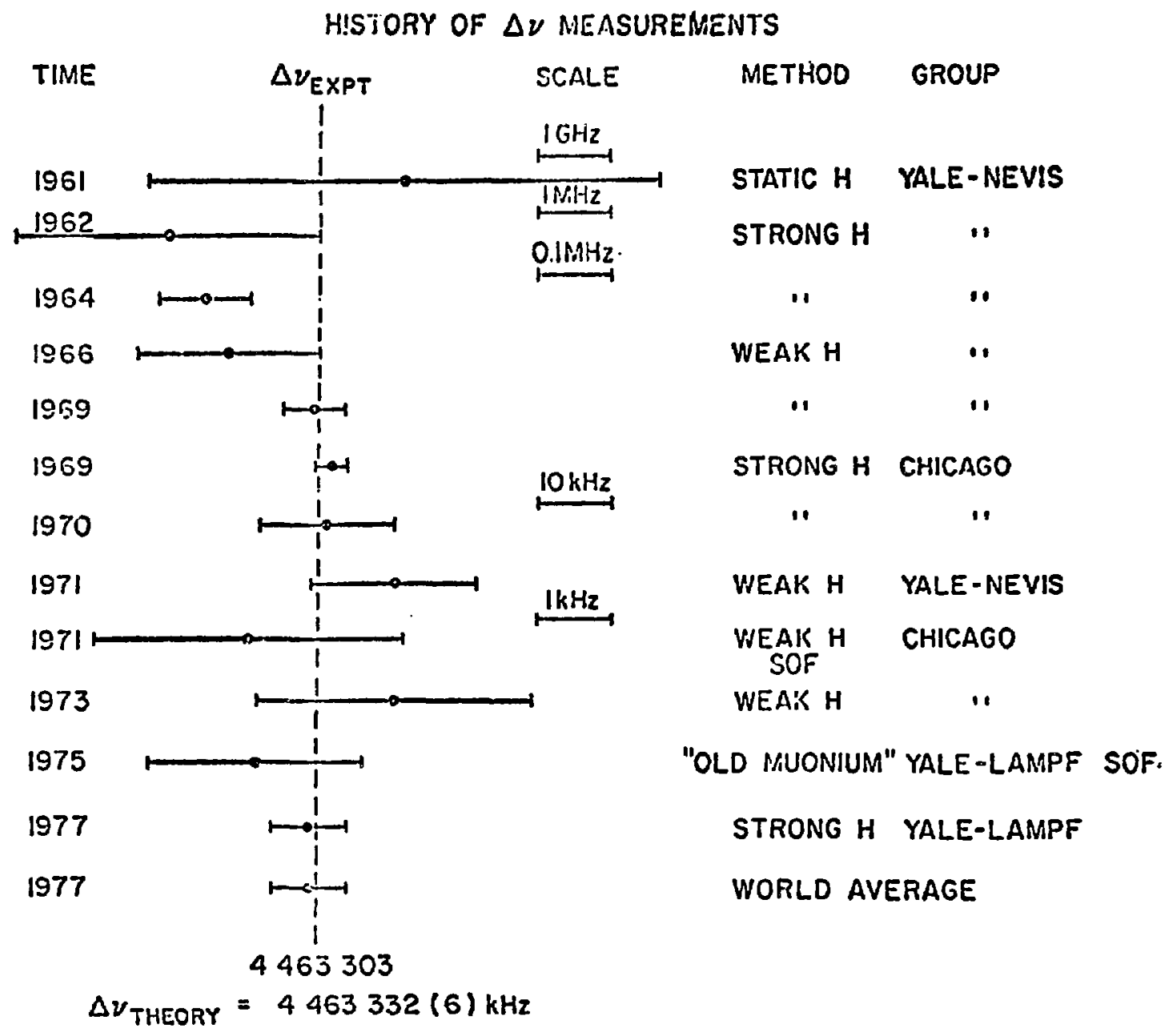

Fig. 15. History of measurements of hyperfine splitting. 
THE $\left(\pi^{*}, \pi^{-}\right)$REACTION ON A NUCLEUS CHANGES TWO NEUTRONS INTO TWO PROTONS:

$$
Z^{A} N^{\left(\pi^{*}, \pi^{-}\right)} Z+2^{A} N-2
$$

THE CROSS-SECTION $d C / d \Omega\left(0^{\circ}\right)$ WAS OBSERVED BY USING A PION CHAINISL AS BOTH A $\pi^{\circ}$ CHANNEL (I5T HALF) AND AT SFECTROMETER (2 ND MALF):
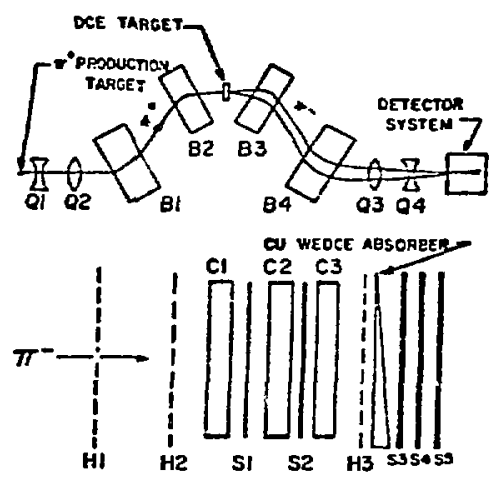

HI-3 helical WIRE chambers

Cl-3 PLASTIC cefeHKoV counters

SI-5 SCINTILLATOR COUNTERS

DETAILS OF DETECTOR SYSTEM

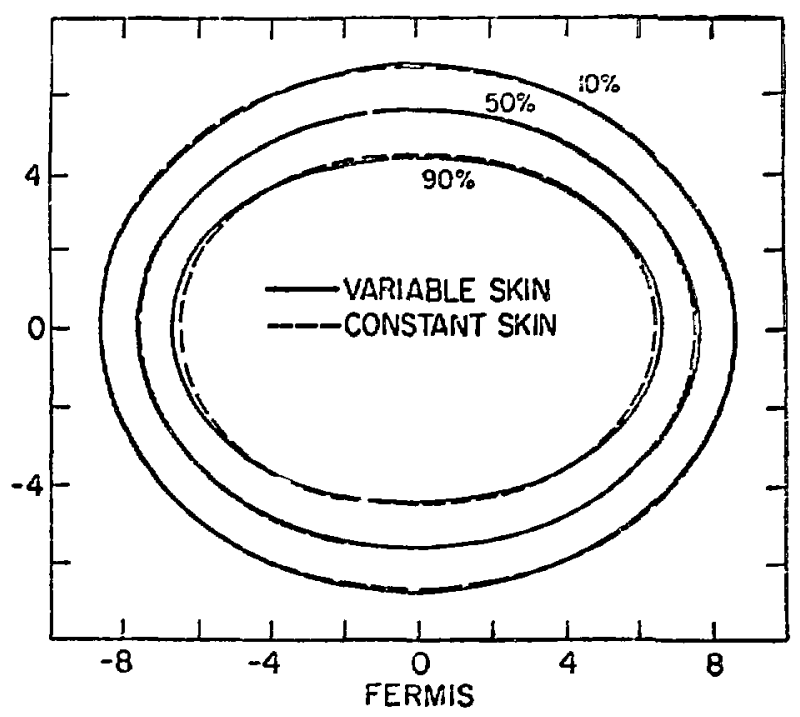

Fig. 18. Contour plots of ${ }^{165} \mathrm{Ho}$ charge distribution.

Fig. 16. Schematic of Low Energy Pion Channel (LEP).

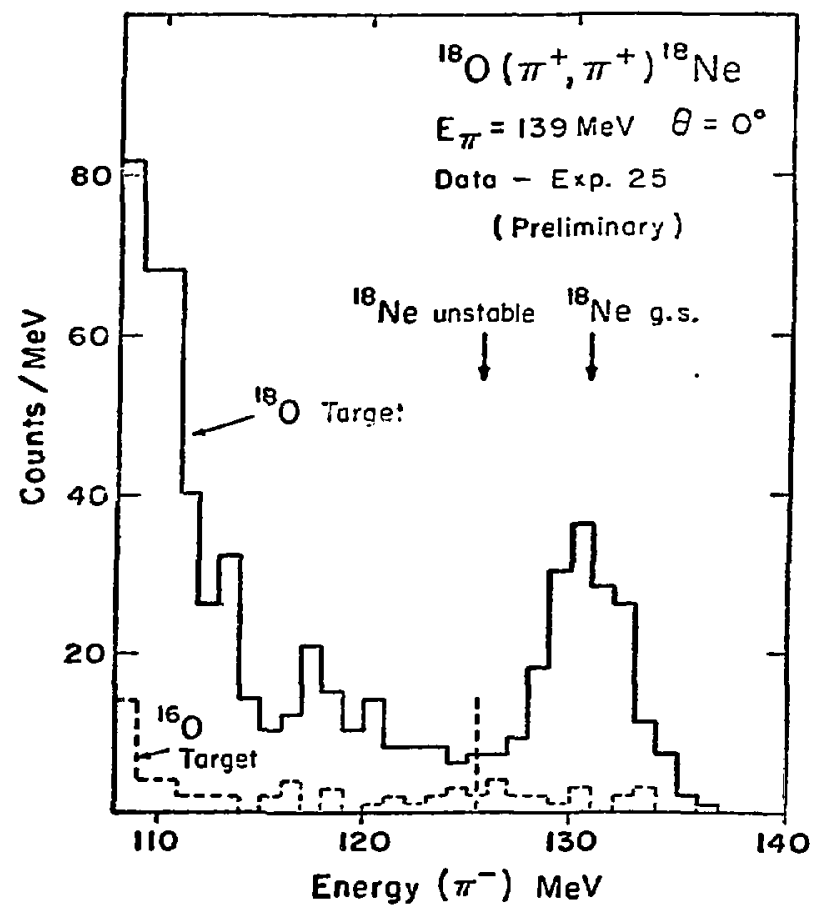

Fig. 17. First results on LEP. 


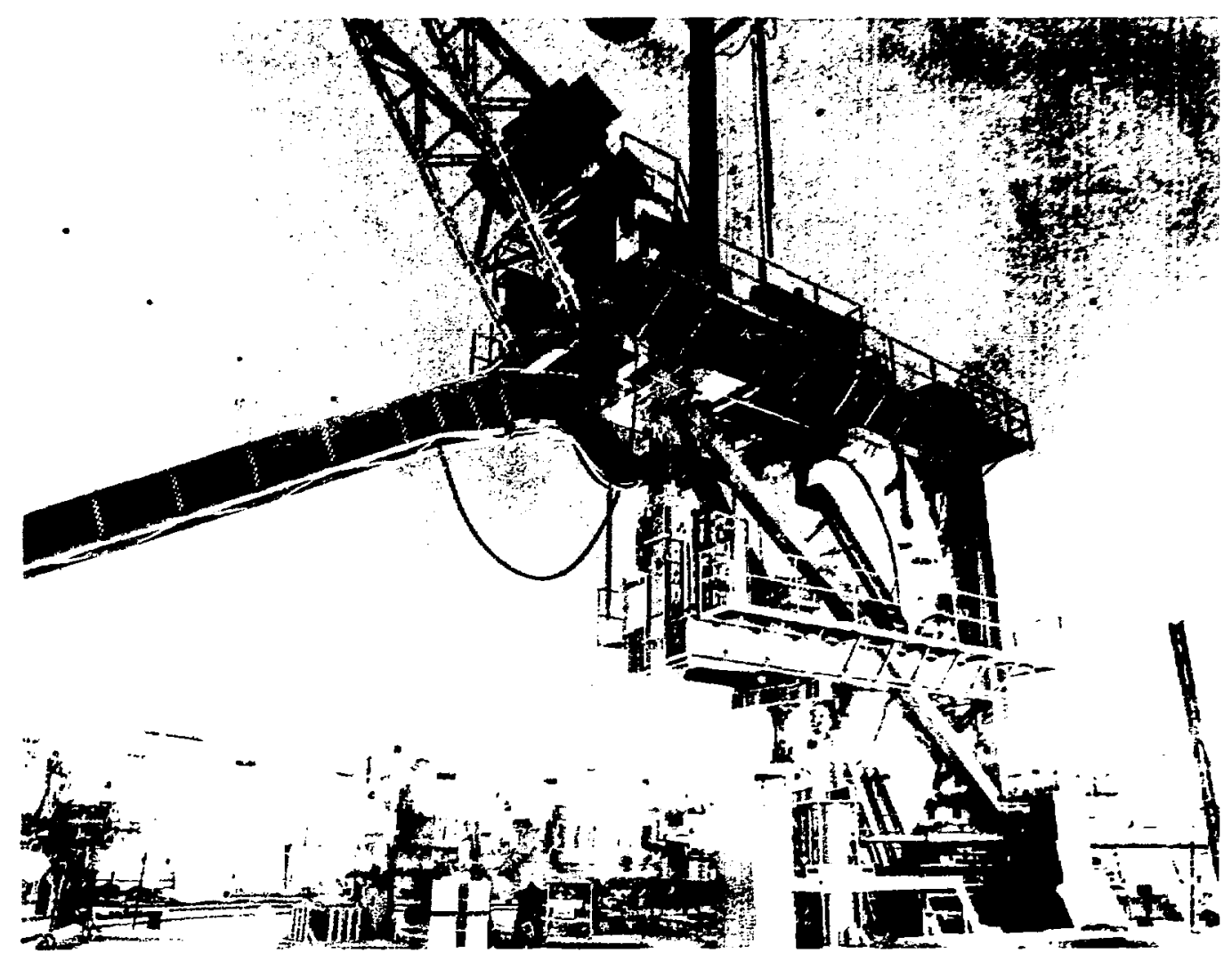

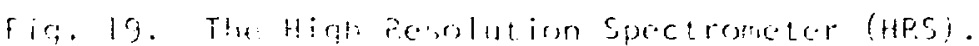




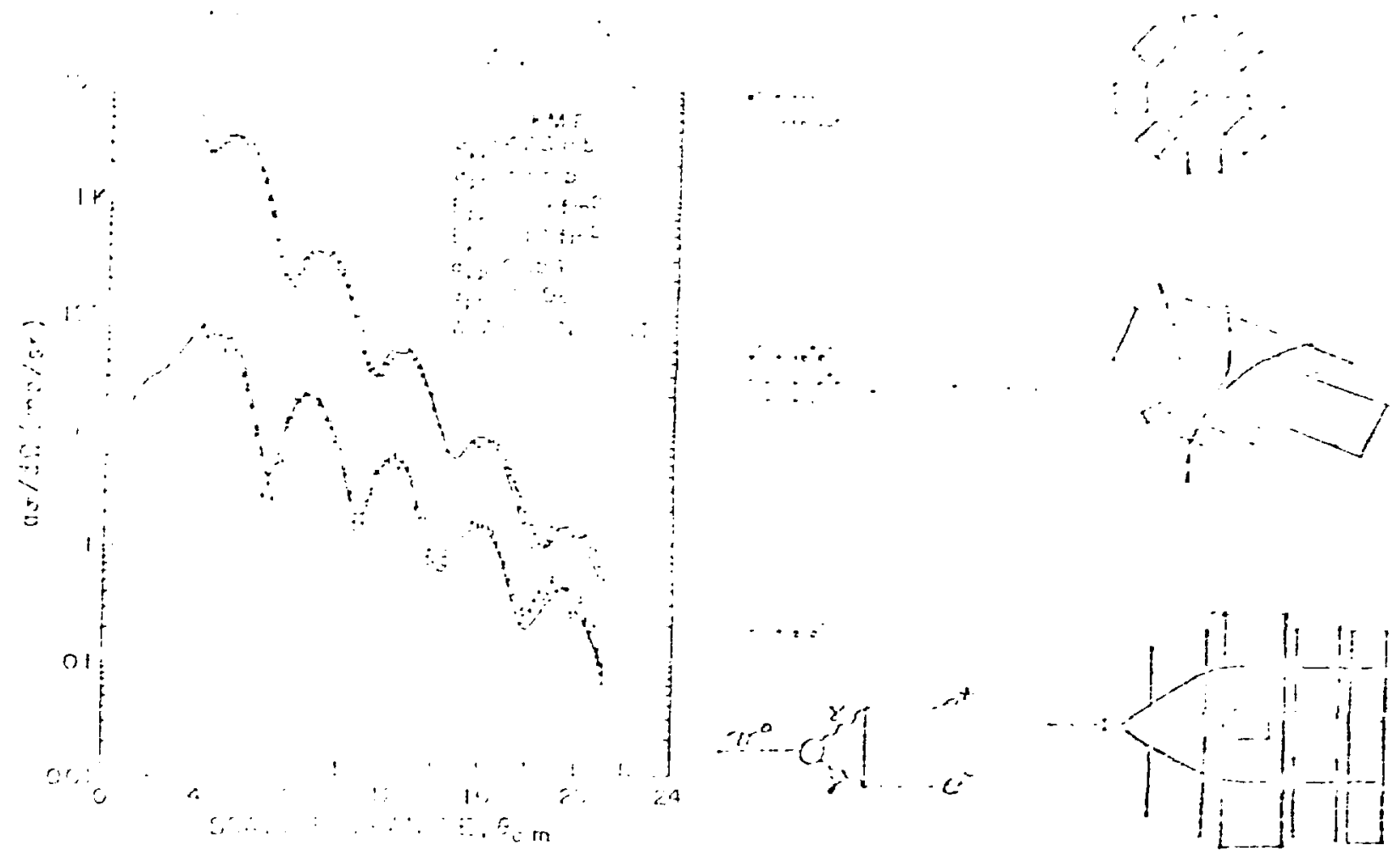

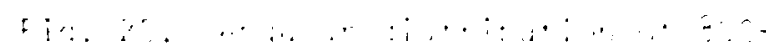

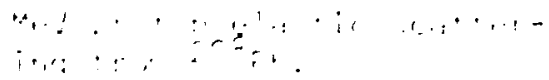

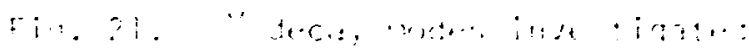
at inint.
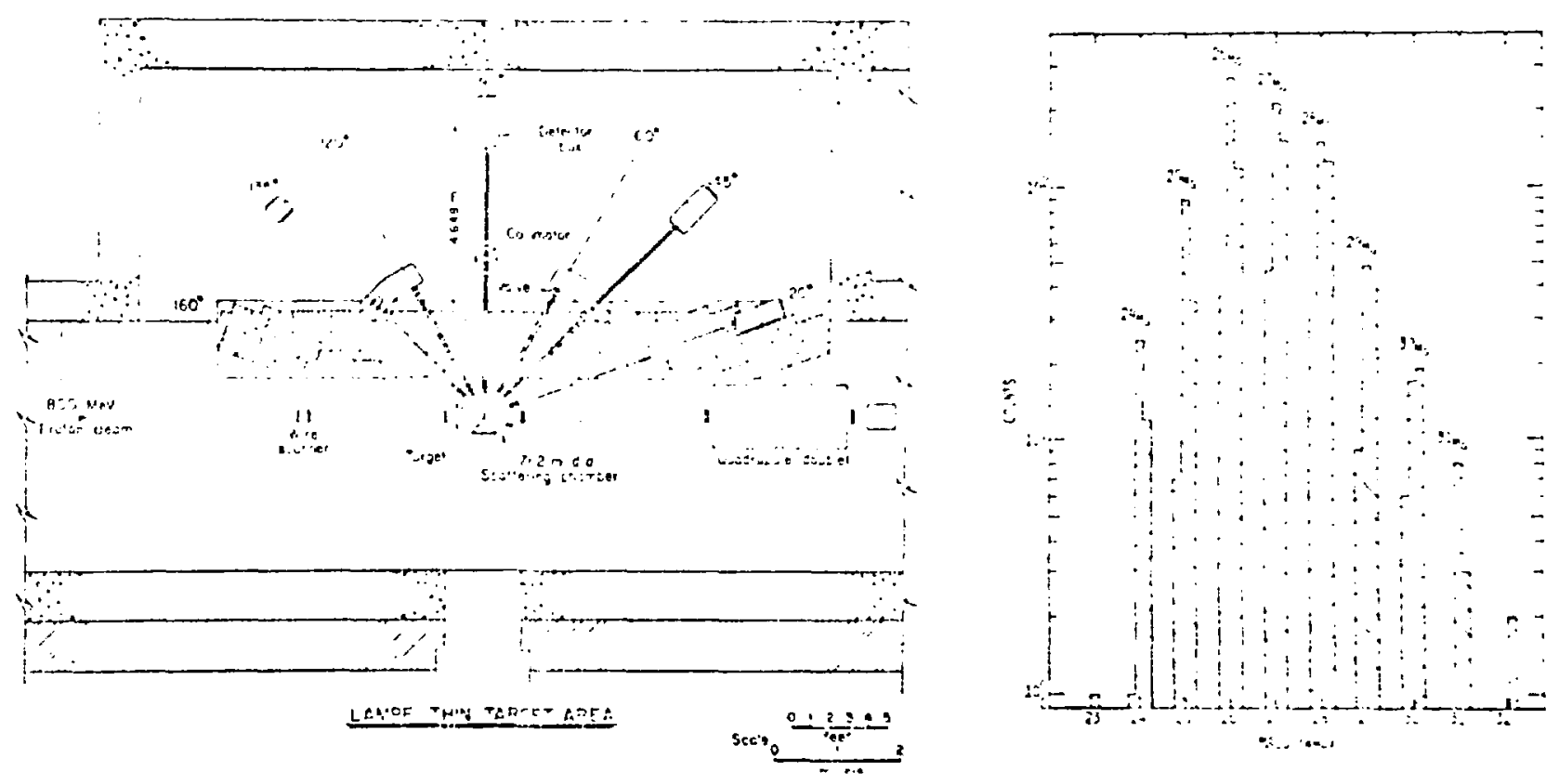

Fig. 22. LAMPF thin target area for study of spallation products. 


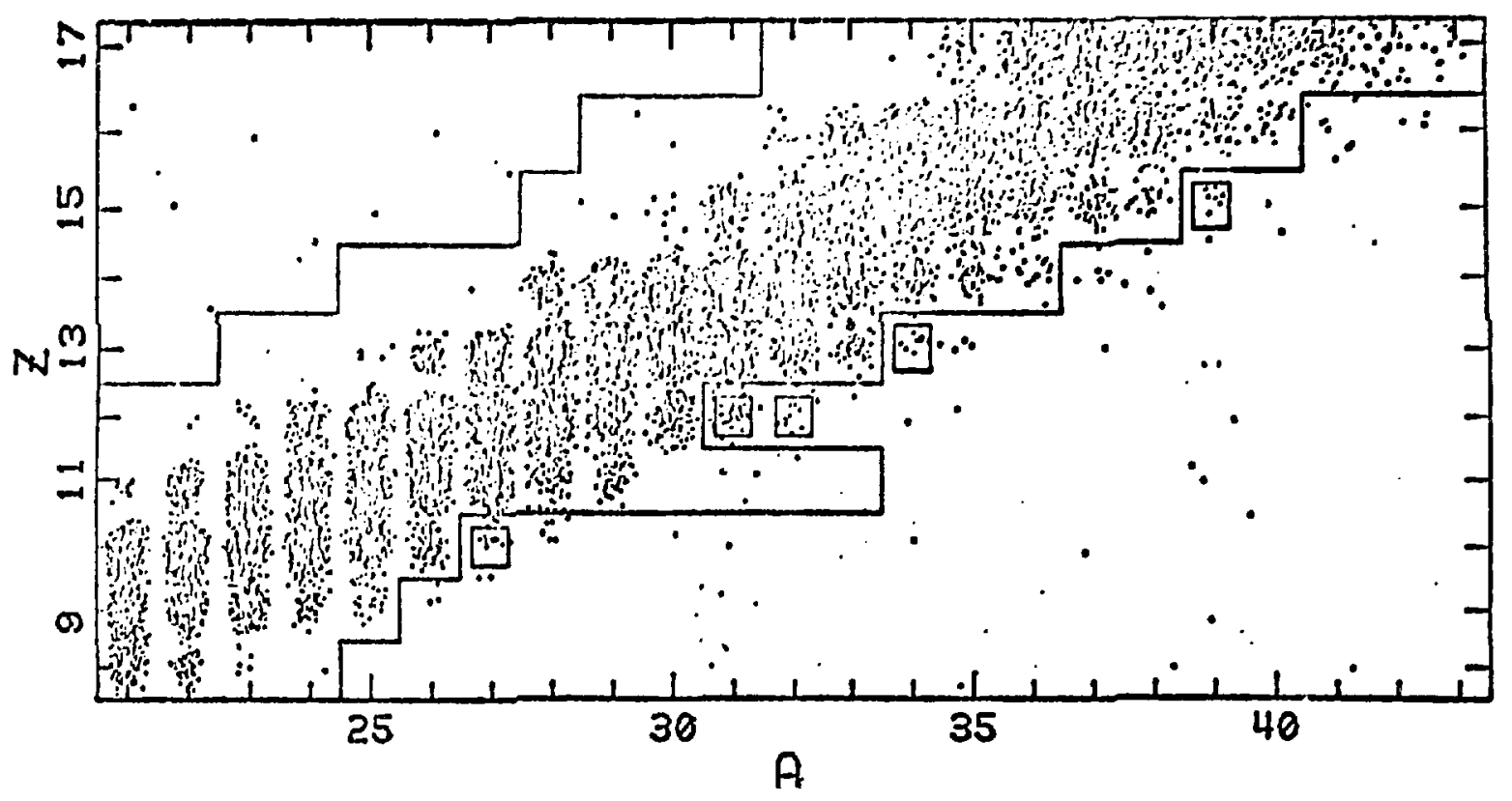

Fig. 23. Mass distribution for isotopes of $\mathrm{Ne}, \mathrm{Mg}, \mathrm{Al}$, and $\mathrm{P}$.

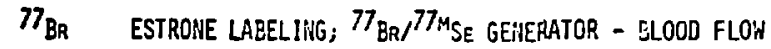

MEASUREHENTS

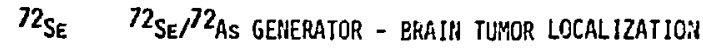

$82_{S_{R}} \quad{ }^{82} S_{R R} / 32_{R B}$ GENERATOR - MYOCARD IAL IHAG LilG E.G., DELINEATE IiHFARCT

123. I. IMAGING OF ORGANS

${ }^{68_{G E}} \quad 68_{G E} / 68_{G A}$ GEHEPATOR - DETECT LMMPHATIC TUMORS

127 Xe LUHG PERfusion aid VERTILATION STUDIES; BRAIII BLOOD FLOW STUDIES

$172_{\mathrm{HF}} \quad 172_{\mathrm{HF}} / 172_{\text {LU GEHERATOR - CHEMICAL LABELLiiG OF RARE }}$ EARTHS AND III VIVO ANIMAL STUDIES

${ }^{44} \mathrm{TI}_{\mathrm{I}} \quad{ }^{44} \mathrm{~T}_{1} \mathrm{~s}^{44} \mathrm{SC}$ GERERATOR - BOHE IMAGIIIG

${ }^{67}$ Cu LABELING OF BLEOMYCIN - CHENOTHERAPEUTIC AGENT FOR MELONOMA; TRACE ELEMERT IN BODY

88Y PHOTONEUTRON SOURCE FOR SAFEGUARDS

$26_{\text {AL }}$ GEOCHEMICAL STUDIES

Fig. 24. Radionuclides under development at LAMPF. 


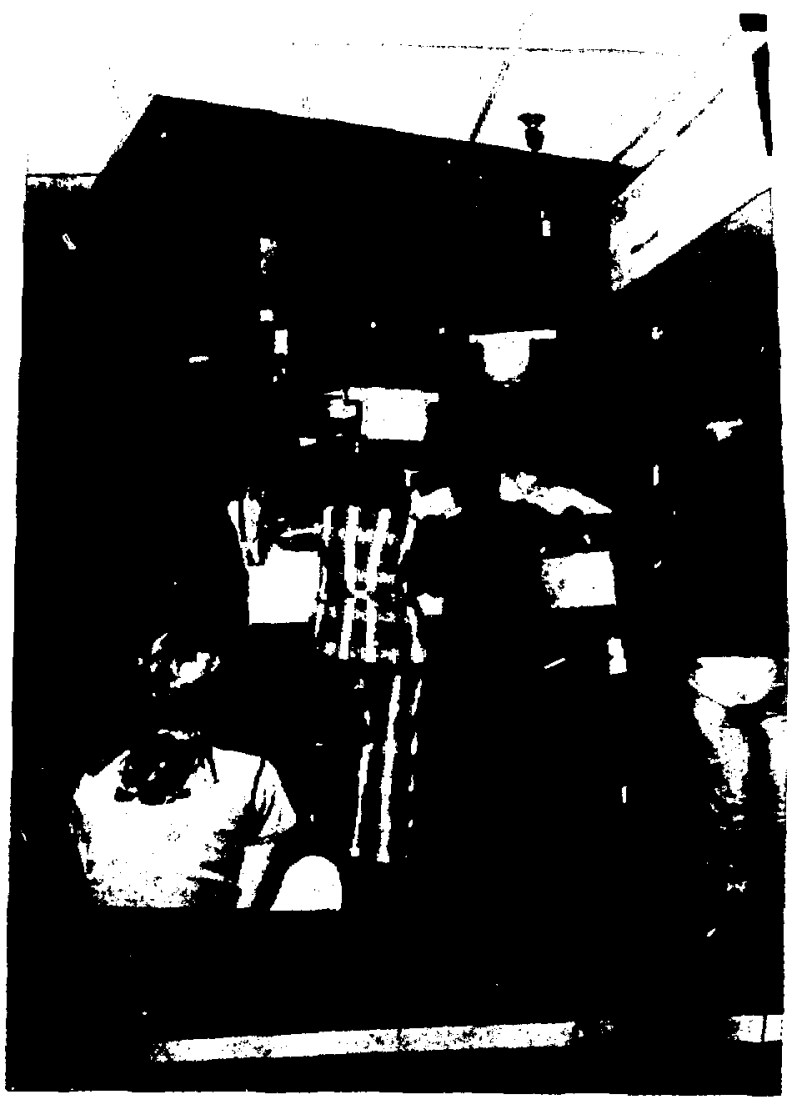

Fig. 25. First patient being treated at biomedical channel.

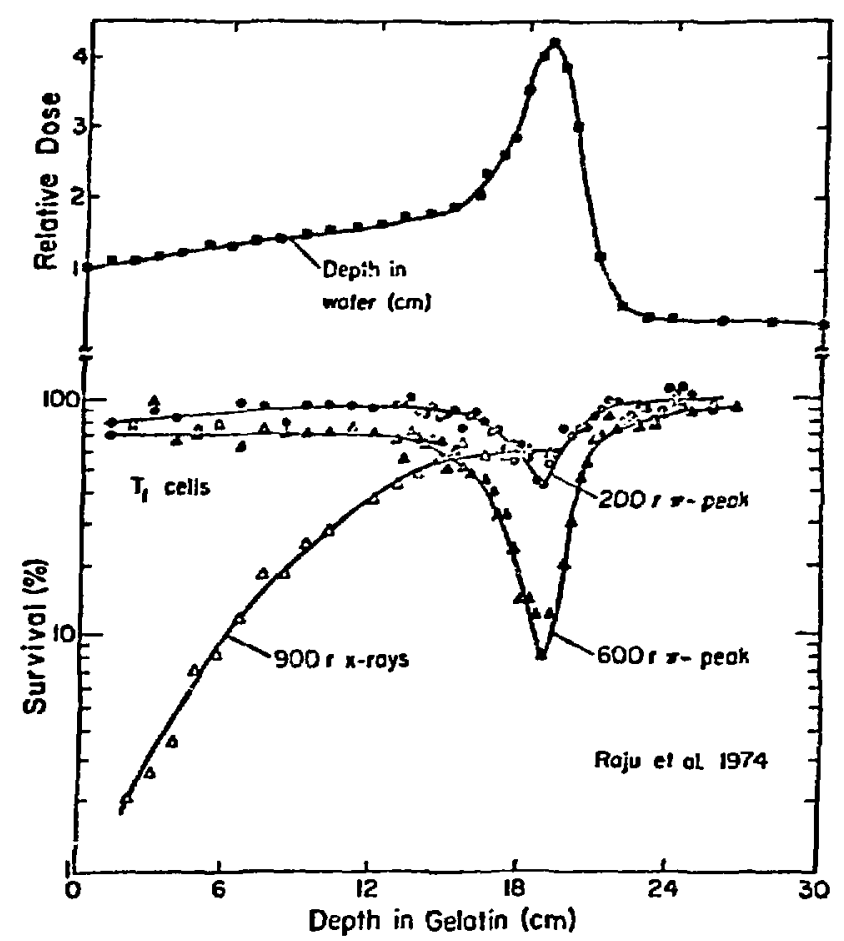

Fig. 26. Survival curves for T-1 human kidney cells when irradiated by $x$ rays and negative pions. 


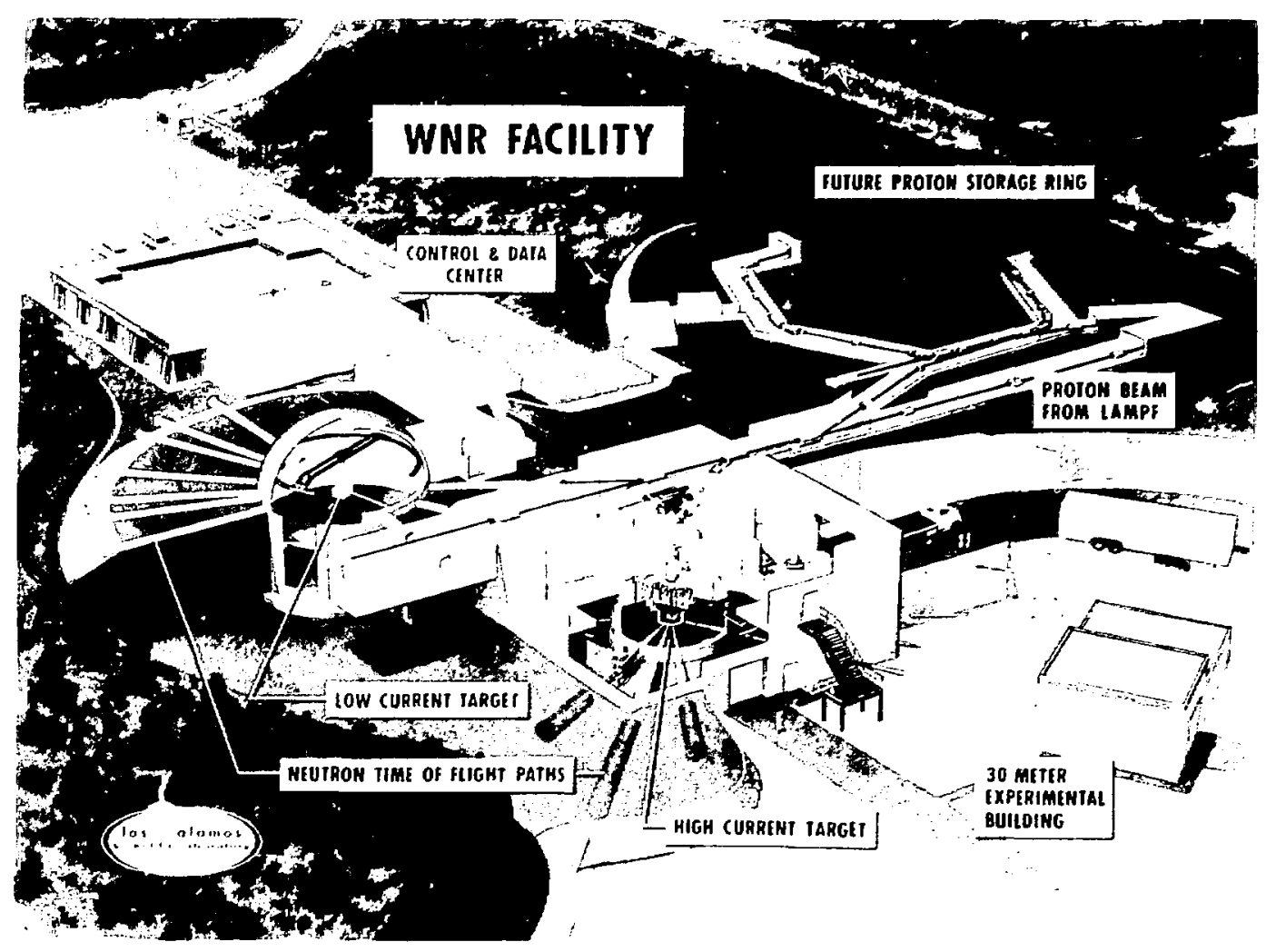

Fig. 27. Weapons Neutron Research Facility (WNR). 


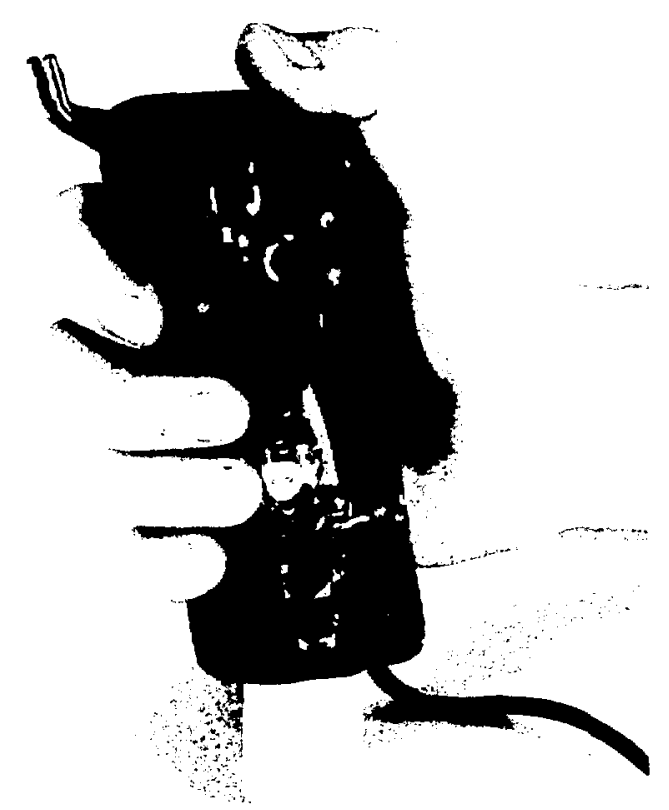

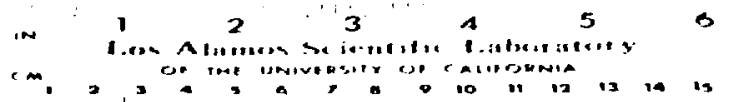

Fig. 28. Circuil for localized $r f$ heating for controlling tumior growth.

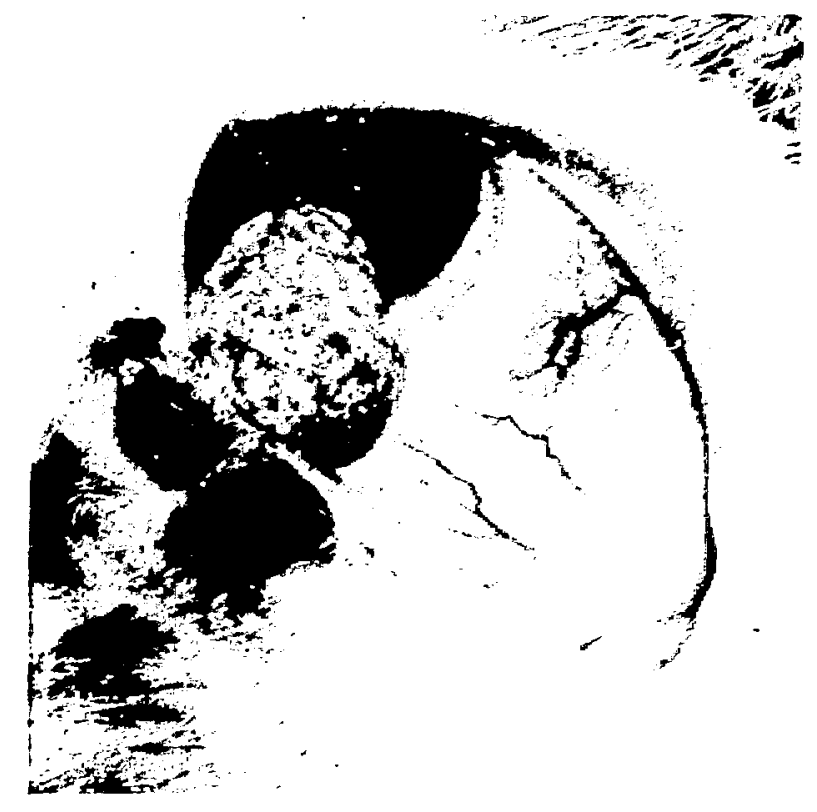

Fiq. 29. Eve iunor prevalen among cattle in the southuest.

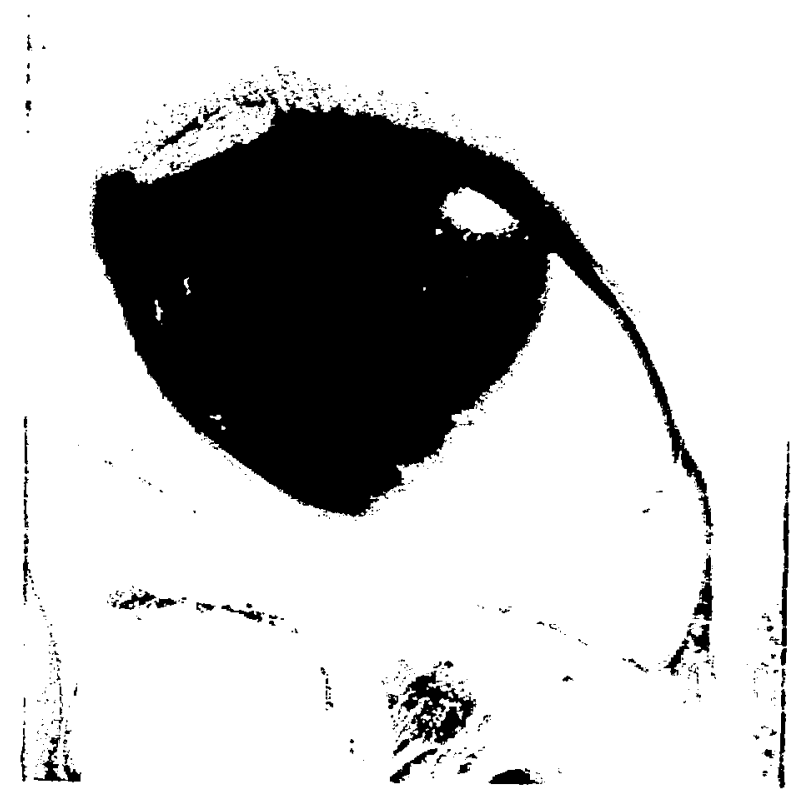

Fig. 30. Eye tumor after 10 weeks of treatment. 


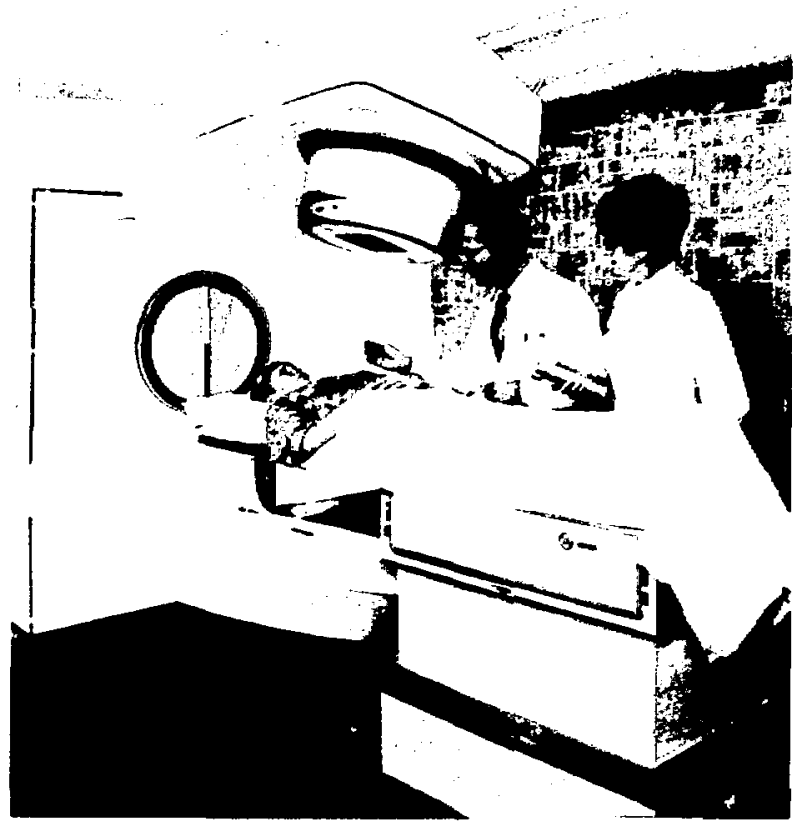

Fig. 31. Varian's "Clinac," utilizing LASL-invented waveguide accelerator concept.

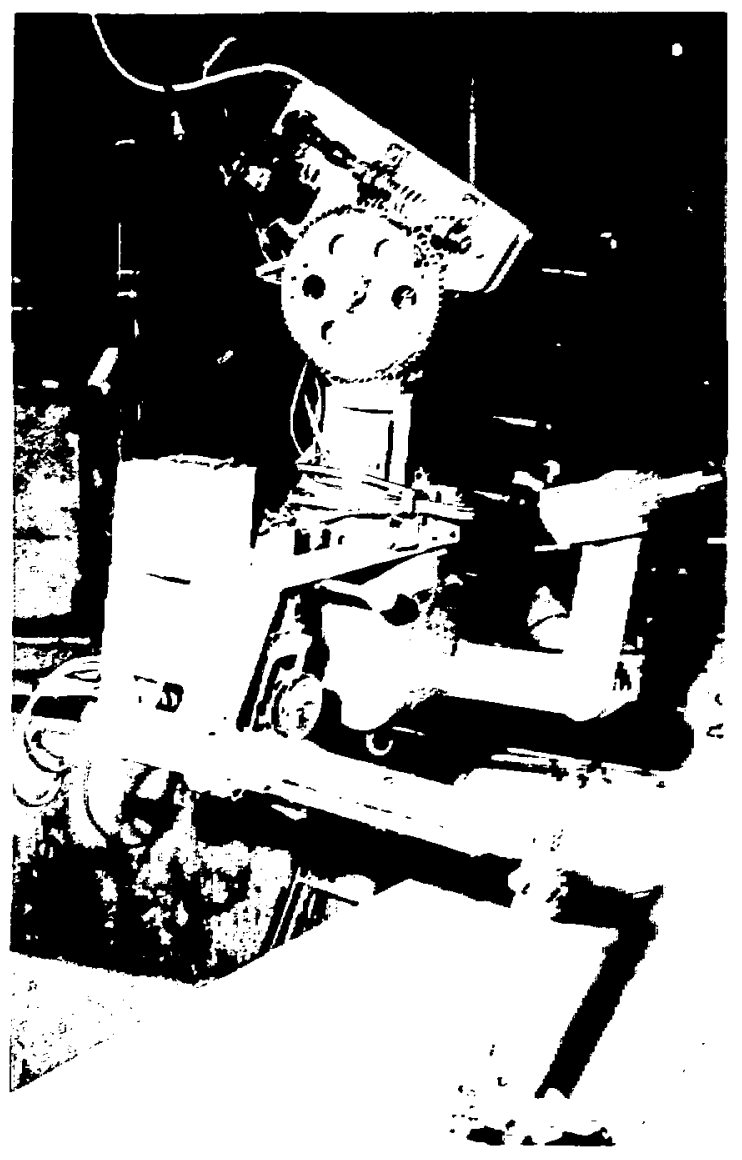

Fig. 32. Remote handling equioment 


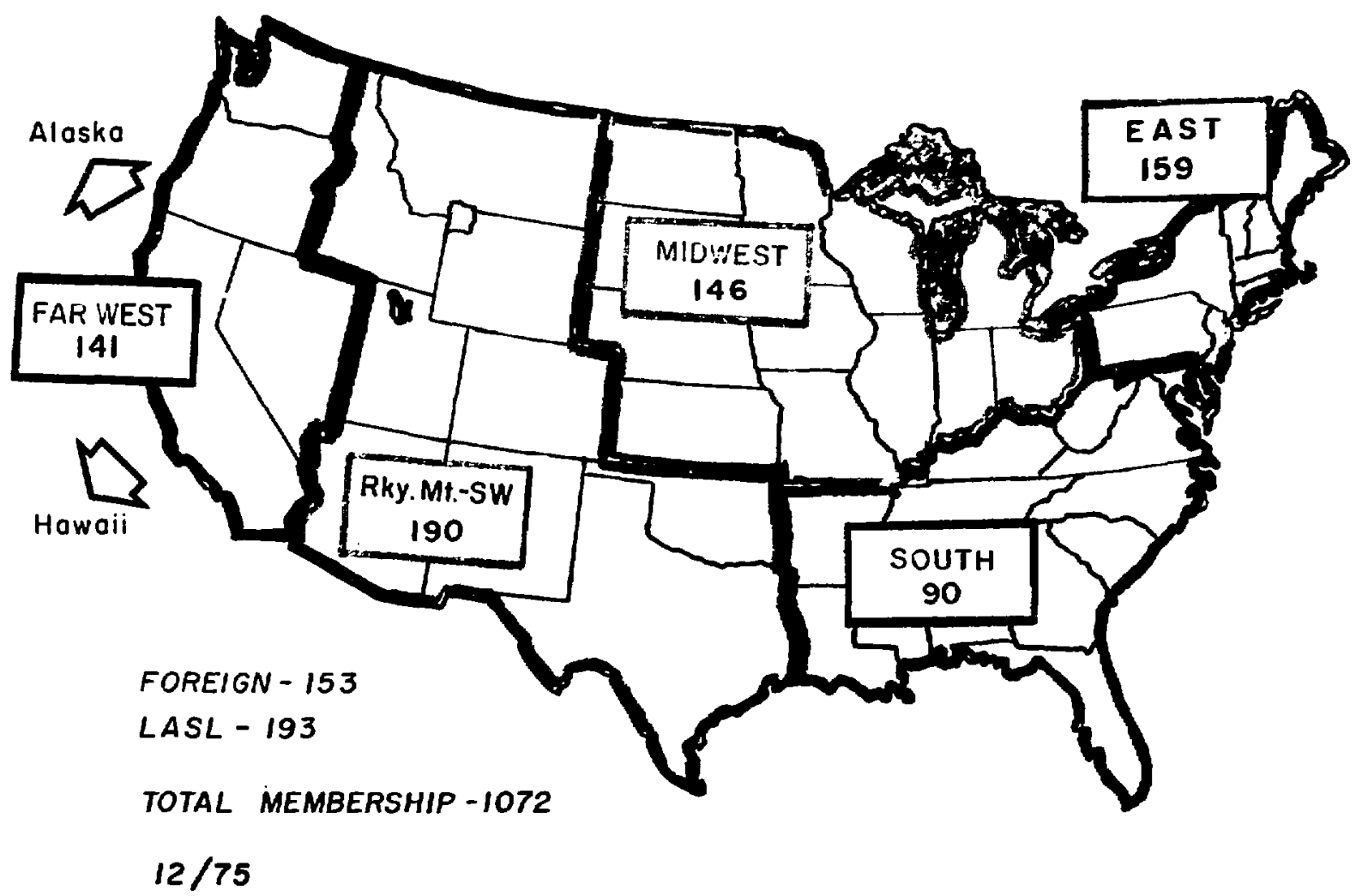

Fig. 33. Regional distribution of LAMPF users.

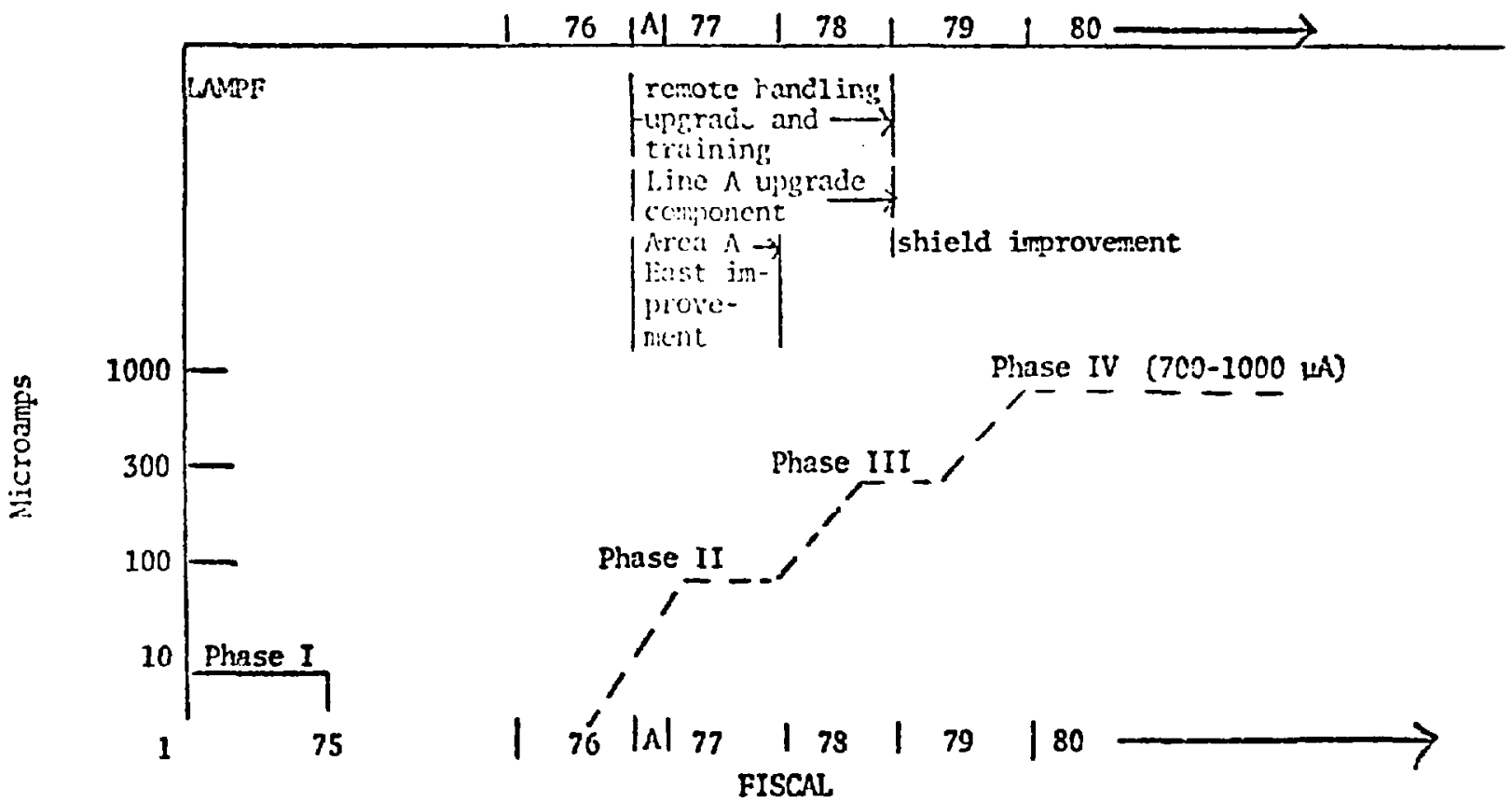

Fig. 34. Schedule for LAMPF current upgrading. 


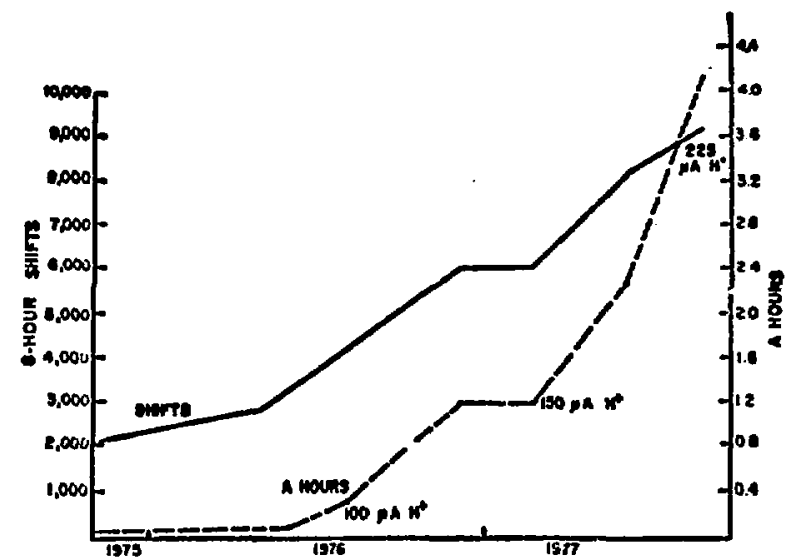

Fig. 35. Cumulative LAMPF beam for experiments.

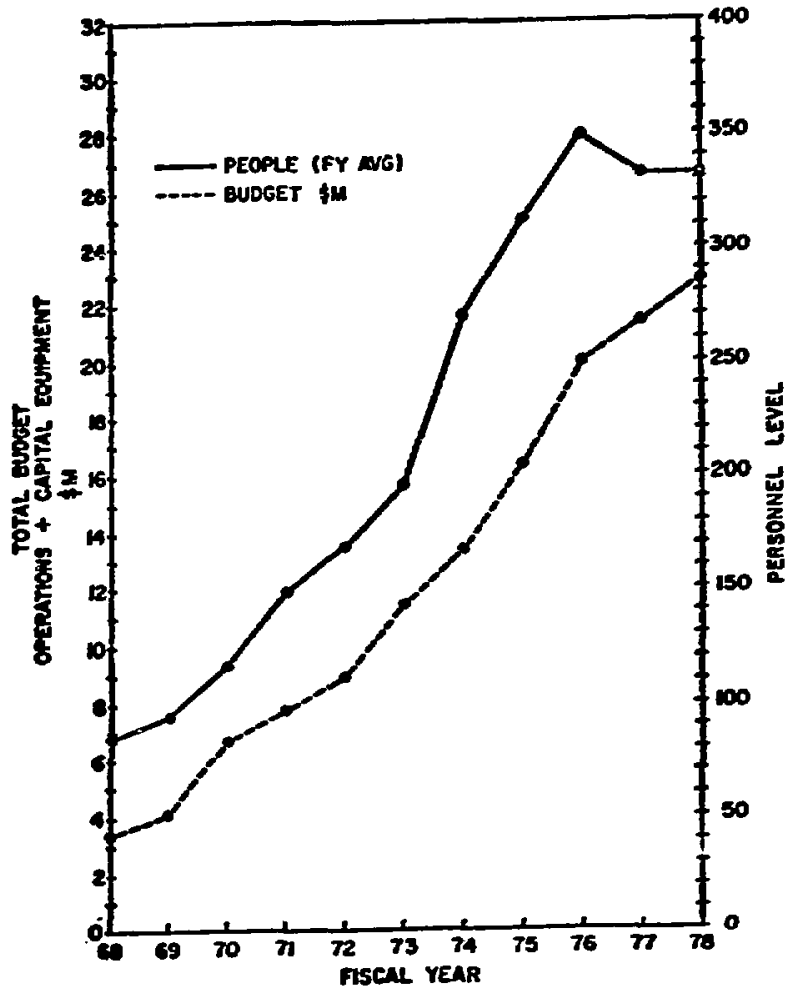

Fig. 36. Budgetary history of LAMPF.

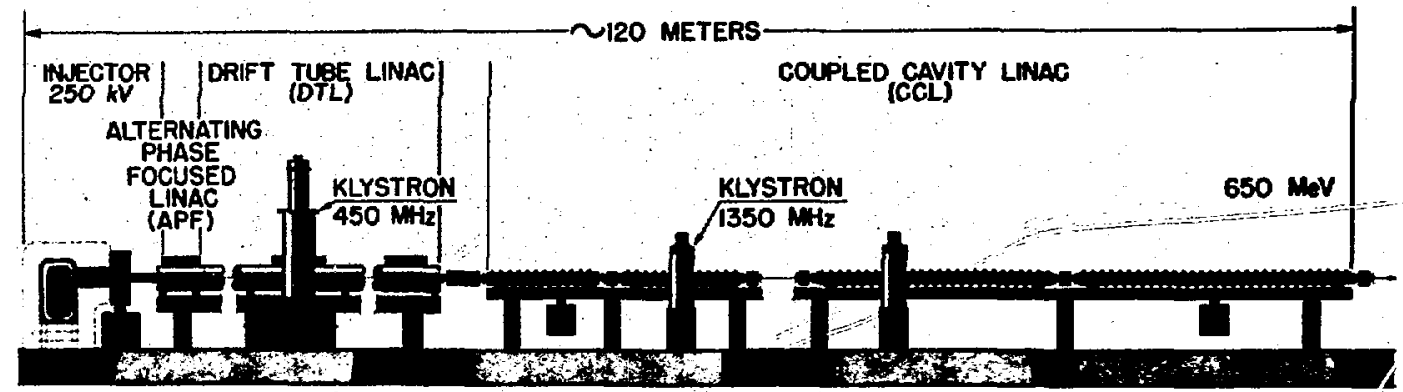

MANOR TECHNICAL INNOVATIONS

HIGHER FREQUENCY

HIGHER GRADIENT

ALTERNATING PHASE FOCUSING

LOWER INUECTION ENERGY

DOUBLE HARMONIC BUNCHER

PERMANENT-MAGNETIC

OUADRUPOLES

DISK \& MASHER LMAC STRUCTUAE

RF MANHFOLD POWER DISTRIBUTION

DISTRIBUTED MCROPROCESSOR CONTROL
PROTON BEAM PARAMETERS
INJECTION ENERGY

FINAL ENERGY

PEAK BEAM CURRENT

PULSE LENGTH

REPETITION RATE

AVERAGE BEAM CURAENT

PROTON LINAC PARAMETERS

FREQUENGY APF Q DTL SECTION

COUPLED CAVITY SECTION

CRADIENT

TRANSITION ENERGIES
APF \& DTL SEGTION

APFIOTL
$250 \mathrm{kNN}$

$650 \mathrm{meN}$

$30 \mathrm{ma}$

$10 \mathrm{~ms}$

$360 \mathrm{~Hz}$

$100 \mathrm{~mA}$
$450 \mathrm{Mz}$

$1350 \mathrm{MHz}$

$6 \mathrm{cmm}$

7 Mry

$150 \mathrm{int}$

Fig. 37. Pion generator for medical irradiation (PIGMI). 